Document downloaded from:

http://hdl.handle.net/10251/36550

This paper must be cited as:

Molina Puerto, J.; Fernández Sáez, J.; Del Río García, Al.; Bonastre Cano, JA.; Cases Iborra, FJ. (2012). Characterization of azo dyes on Pt and Pt/polyaniline/dispersed Pt electrodes. Applied Surface Science. 258:6246-6256. doi:10.1016/j.apsusc.2012.02.150.

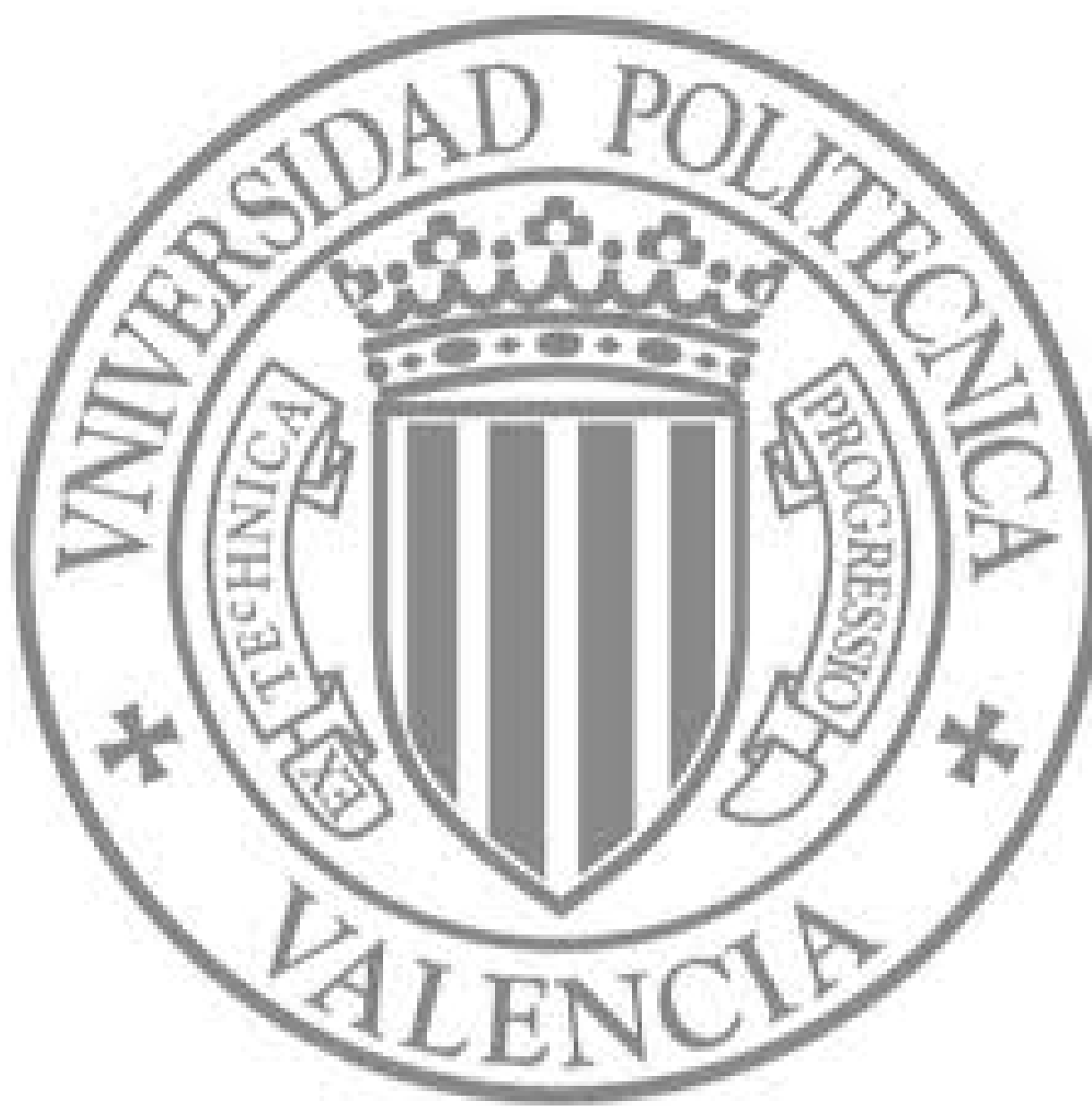

The final publication is available at

http://dx.doi.org/10.1016/j.apsusc.2012.02.150

Copyright Elsevier 


\title{
Characterization of azo dyes on Pt and Pt/polyaniline/dispersed Pt electrodes
}

\author{
J. Molina, J. Fernández, A.I. del Río, J. Bonastre, F. Cases* \\ Departamento de Ingeniería Textil y Papelera, EPS de Alcoy, Universitat Politècnica \\ de València, Plaza Ferrándiz y Carbonell s/n, 03801 Alcoy, Spain
}

\begin{abstract}
The electrochemical characterization of two organic dyes (amaranth and procion orange MX-2R) has been performed on Pt electrodes and Pt electrodes coated with polyaniline and dispersed Pt. Electrodes with different Pt loads have been synthesized and characterized obtaining that a load of $300 \mu \mathrm{g} \mathrm{cm}{ }^{-2}$ was the optimum one. Scanning electron microscopy (SEM) and atomic force miscroscopy (AFM) was employed to observe the distribution and morphology of the Pt nanoparticles. The electroactivity of the electrodes has been also characterized by means of scanning electrochemical microscopy (SECM). The chemical characterization of Pt dispersed Pani coated Pt electrodes (Pt-Pani-Pt) was performed by means of X-ray photoelectron spectroscopy (XPS). The electrochemical characterization of the dyes has been performed by means of cyclic voltammetry. Voltammograms have shown that the presence of the dyes diminishes characteristic Pt oxidation and reduction peaks. However, redox processes due to the dyes, appeared in the voltammograms. The different species responsible of these redox processes were generated in the vicinity of the electrode and were not adsorbed on the electrode surface since after stirring, the different redox processes disappeared. Characterization with different scan rates showed that redox processes of both dyes were controlled by diffusion.
\end{abstract}


Keywords: dispersed platinum, polyaniline, scanning electrochemical microscopy, atomic force microscopy, dye, cyclic voltammetry.

\footnotetext{
* Corresponding author. Fax.: +34 966528438; telephone: +34 966528812.

E-mail address: fjcases@txp.upv.es (Prof. F. Cases).
}

\section{Introduction}

The dispersion of $\mathrm{Pt}$ on different substrates has been employed as a procedure to increase the electroactivity of the electrodes by increasing their specific area with the $\mathrm{Pt}$ nanoparticles. The same effect of a bare Pt surface can be reached with a dispersion of Pt $\left(<100 \mu \mathrm{g} \mathrm{cm}^{-2}\right)$ [1]. Different substrates have been employed to deposit $\mathrm{Pt}$ nanoparticles on them, like: graphene [2], carbon nanotubes [3], carbon nanofibers [4], graphite [5], pyrolitic graphite [6,7], carbon cloth [8], titanium [9] or conducting polymers [10-16]. Several methods have been employed to deposit Pt nanoparticles [16]; however the electrochemical methods are among the most employed. The reason is that electrochemical methods are efficient and the deposition process can be easily controlled. The most employed methods are constant potential deposition [5$9,11,12,14,16]$ and cyclic voltammetry deposition $[4,10,12,13]$. Conducting polymers are appropriate substrates to perform the synthesis of Pt nanoparticles because they present a porous structure with high surface area, as well as a good conductivity. Either polyaniline (Pani) $[10,12,14,16]$ or polypyrrole (PPy) have been employed $[11,13,15]$. Pt dispersion on conducting polymers has demonstrated to increase the electroactivity of the coatings when oxidizing small organic molecules like methanol [10-16]. This electroactivity towards methanol oxidation makes these catalysts interesting in fuel cells 
applications. Dispersed Pt has also the advantage that Pt poisoning by adsorption of $\mathrm{CO}$ species on the surface is also lesser than in the case of bare Pt surfaces [10]. However, very little has been reported about the employment of dispersed Pt on conducting polymers in the characterization of higher size molecules, such as organic dyes. Regarding organic dyes, different studies have been performed employing different electrode materials $[17,18]$. Activated carbon fibers $[19,20]$ or carbon paste electrodes [21] have been employed in the characterization and the degradation of amaranth; in the case of procion orange $\mathrm{MX}-2 \mathrm{R} \mathrm{Ti} / \mathrm{SnO}_{2}-\mathrm{Sb}$-Pt anodes have been employed for this purpose in our previous study [22]. Nevertheless, to the best of our knowledge, Pt nanoparticles supported on conducting polymers have not been employed in these types of studies.

The electrochemical characterization of two organic dyes on $\mathrm{Pt}$ electrodes and $\mathrm{Pt}$ electrodes coated with polyaniline and dispersed Pt has been performed by cyclic voltammetry $(\mathrm{CV})$. The electrochemical characterization has the aim to establish the adequate potentials and strategy to carry out the electrolysis of dye solutions. The dyes employed for the study have been amaranth and procion orange MX-2R (PMX2R). The electroactivity of the electrodes has been also measured by scanning electrochemical microscopy (SECM). SECM is a relatively novel (1989) and powerful technique that is becoming more popular among researchers [23-25]. This technique allows zonal analysis of electroactivity without polarizing the sample to study. Scanning electron microscopy (SEM) and atomic force microscopy (AFM) has been employed to observe the morphology and distribution of the $\mathrm{Pt}$ nanoparticles. X-ray photoelectron spectroscopy (XPS) measurements have been employed to perform elemental analyses. 


\section{Experimental}

\subsection{Reagents and materials}

All reagents employed were of analytical grade. Aniline $\left(\mathrm{C}_{6} \mathrm{H}_{5} \mathrm{NH}_{2}\right)$, sulphuric acid $\left(\mathrm{H}_{2} \mathrm{SO}_{4}\right)$ and hexachloroplatinic acid hexahydrate $\left(\mathrm{H}_{2} \mathrm{PtCl}_{6} \cdot 6 \mathrm{H}_{2} \mathrm{O}\right)$ were purchased from Merck. Hexaammineruthenium (III) chloride $\left(\mathrm{Ru}\left(\mathrm{NH}_{3}\right)_{6} \mathrm{Cl}_{3}\right) 98 \%$ and anhydrous sodium sulphate $\left(\mathrm{Na}_{2} \mathrm{SO}_{4}\right)$, were used as received from Acrōs Organics and Merck respectively. Pt wires $(0.5 \mathrm{~mm}$ diameter, $99.99 \%$ purity $)$ were acquired from Engelhard-Clal. Amaranth and procion orange MX-2R were supplied by Fluka and Zeneca, respectively.

When needed, solutions were deoxygenated by bubbling nitrogen $\left(\mathrm{N}_{2}\right.$ premier X50S). Ultrapure water was obtained from an Elix 3 Millipore-Milli-Q Advantage A10 system with a resistivity near to $18.2 \mathrm{M} \Omega \mathrm{cm}$.

\subsection{Synthesis of polyaniline on Pt electrodes (Pt-Pani)}

All electrochemical experiments were performed at room temperature. Synthesis of polyaniline on $\mathrm{Pt}$ wires was performed in $0.1 \mathrm{M}$ aniline and $0.5 \mathrm{M} \mathrm{H}_{2} \mathrm{SO}_{4}$ aqueous solution. A three electrode configuration was employed. The counter electrodes (CE) employed were made of stainless steel (chemical composition in weight (\%): C 60.050, Si 0.750, Mn 6 2.000, P 0.040, S 0.015, Cr 18-19, Cu 8.5-9). Their pre-treatment consisted on polishing, degreasing with acetone in ultrasonic bath and washing with water in an ultrasonic bath. In electrochemical synthesis, two CE were used to equalize the electrical field around the working electrode (WE). The reference electrode employed was an $\mathrm{Ag} / \mathrm{AgCl}(3 \mathrm{M} \mathrm{KCl})$. The working electrode was a wire of $\mathrm{Pt}(5 \mathrm{~cm}$ length). The platinum electrode required a flame thermal treatment to clean its surface before each electrochemical experiment according to the method developed by Clavilier 
[26]. Polyaniline synthesis was performed potentiodynamically between $-0.125 \mathrm{~V}$ and $+0.875 \mathrm{~V}$ for 13 scans. With 13 scans the thickness of the coating obtained has been estimated to be $\sim 0.4 \mu \mathrm{m}[10]$. This thickness has been considered to synthesize later dispersed Pt on polyaniline. Thicker coatings would impede the observation of Pt and dye processes in cyclic voltammetry due to the higher intensity of the redox processes of polyaniline in the voltammograms.

\subsection{Synthesis of dispersed platinum on Pt-Pani electrodes (Pt-Pani-Pt)}

Synthesis of dispersed Pt on Pt-Pani electrodes was performed in $5 \mathrm{mM} \mathrm{H} \mathrm{H}_{2} \mathrm{PtCl}_{6} \cdot 6 \mathrm{H}_{2} \mathrm{O}$ in $0.5 \mathrm{M} \mathrm{H}_{2} \mathrm{SO}_{4}$ aqueous solution. The same three electrode configuration than in polyaniline synthesis was employed. In this case the working electrode was the Pt-Pani electrode. Synthesis of dispersed Pt was performed potentiostatically from $+0.595 \mathrm{~V}$ (oxidation potential) to $-0.105 \mathrm{~V}$ (reduction potential at which Pt deposition occurs) [16]. The area of the electrode was controlled with Teflon ${ }^{\circledR}$ to control the amount of Pt deposited. The deposition continued during the necessary time to achieve the desired $\mathrm{Pt}$ load. Different Pt loads $\left(\mu \mathrm{g} \mathrm{cm}^{-2}\right)$ were obtained by controlling the electrical charge applied (300, 600, 900 and $\left.1200 \mathrm{mC} \mathrm{cm}^{-2}\right)$.

\subsection{Scanning electron microscopy (SEM)}

A Jeol JSM-6300 scanning electron microscope was employed to observe the morphology of the samples. Scanning electron microscopy (SEM) analyses were performed using an acceleration voltage of $20 \mathrm{kV}$. Samples for SEM measurements were coated with Au employing a sputter coater Bal-Tec SCD 005.

2.5. Atomic force microscopy measurements (AFM) 
Atomic force microscopy (AFM) was used to determine surface topography, topographic profiles and the roughness of the different samples. AFM analyses were performed with a multimode AFM microscope with a Nanoscope ${ }^{\circledR}$ IIIa ADCS controller (Veeco Metrology Group). A monolithic silicon cantilever (FESP, tip radius 8 $\mathrm{nm}$, Bruker AFM probes) with a constant force of $2.8 \mathrm{~N} / \mathrm{m}$ and a resonance frequency of $75 \mathrm{kHz}$ was used to work on tapping mode. From the analysis of the images, the 2-D and 3-D representation of the surface of the electrodes was obtained. The root-meansquared roughness (Rrms) was evaluated. Topographic profiles were also obtained for the different samples and they were compared.

\subsection{X-ray photoelectron spectroscopy measurements (XPS)}

XPS analyses were conducted at a base pressure of $5 \cdot 10^{-10}$ mbars and a temperature around $-100{ }^{\circ} \mathrm{C}$. XPS spectra were obtained with a VG-Microtech Multilab electron spectrometer by using unmonochromatized $\mathrm{Mg} \mathrm{K \alpha}(1253.6 \mathrm{eV})$ radiation from a twin anode source operating at $300 \mathrm{~W}(20 \mathrm{~mA}, 15 \mathrm{kV})$. The binding energy (BE) scale was calibrated with reference to the $\mathrm{C} 1 \mathrm{~s}$ line at $284.6 \mathrm{eV}$. C1s, O1s, S2p, N1s, Pt4f and Cl2p core levels XPS spectra were analyzed for Pt-Pani-Pt samples. Taking into account that $\mathrm{H}_{2} \mathrm{PtCl}_{6}$ was used to disperse metallic $\mathrm{Pt}, \mathrm{Pt} 4 \mathrm{f}$ and $\mathrm{Cl} 2 \mathrm{p}$ core level spectra were registered. The $\mathrm{S} 2 \mathrm{p}$ signal was studied because the synthesis solution contained $0.5 \mathrm{M}$ $\mathrm{H}_{2} \mathrm{SO}_{4}$.

\subsection{Scanning electrochemical microscopy (SECM)}

SECM measurements were carried out with a scanning electrochemical microscope of Sensolytics. The three-electrode cell configuration consisted of a $25-\mu \mathrm{m}$-diameter $\mathrm{Pt}$ ultra-microelectrode (UME), a Pt wire auxiliary electrode and an $\mathrm{Ag} / \mathrm{AgCl}(3 \mathrm{M} \mathrm{KCl})$ 
reference electrode. The substrates were wires of $\mathrm{Pt}$ coated with Pani potentiodynamically synthesized (Pt-Pani) and wires of Pt-Pani with dispersed Pt potentiostatically deposited (Pt-Pani-Pt). These substrates were glued to microscope slides with epoxy resin. Due to the cylindrical geometry of the substrate, the initial positioning of the UME tip was achieved by approaching the UME tip to the substrate (z direction) and then by moving the tip perpendicularly over the wire to obtain the point with the highest current variation. Approach curves over this point were then obtained by moving the UME tip in the $\mathrm{z}$ direction.

Two kind of SECM experiments have been carried out. The first one has been done according to the tip generation/substrate collection mode (TG/SC) and the second one with the substrate unbiased at its open circuit potential (OCP). In both experiments a 10 $\mathrm{mM} \mathrm{Ru}\left(\mathrm{NH}_{3}\right)_{6} \mathrm{Cl}_{3}$ and $0.1 \mathrm{M} \mathrm{Na}_{2} \mathrm{SO}_{4}$ aqueous solution was employed. For the TG/SC experiments the $\mathrm{pH}$ was set to 2.3 and for the OCP experiments the $\mathrm{pH}$ was 5.4. In TG/SC mode, the substrate potentials were set at $+0.2 \mathrm{~V}$ and $+0.6 \mathrm{~V}$ and the tip potential was set to $-0.3 \mathrm{~V}$ (conditions for a hexaammineruthenium (III) reduction under diffusion condition).

\subsection{Cyclic voltammetry measurements $(\mathrm{CV})$}

Voltammetric characterization was performed using an Eco-Chemie Autolab PGSTAT302 potentiostat/galvanostat at room temperature. A three electrode electrochemical cell was employed. The system consisted of a Pt counter electrode and an $\mathrm{Ag} / \mathrm{AgCl}(\mathrm{KCl} 3 \mathrm{M})$ reference electrode. Working electrodes employed were either $\mathrm{Pt}$ or Pt-Pani-Pt electrodes. Solutions employed were amaranth $\left(3 \mathrm{~g} \mathrm{~L}^{-1}\right)$ and PMX2R $(4 \mathrm{~g}$ $\mathrm{L}^{-1}$ ) in $0.5 \mathrm{M} \mathrm{H}_{2} \mathrm{SO}_{4}$. Lower concentrations of the dyes were also employed but the intensity of the peaks obtained was quite low. These concentrations of the dyes allowed 
the clear observation of the redox peaks attributed to the dye species. Molecular structures of both azo dyes can be observed in Fig. 1. All solutions were previously degassed by purging with nitrogen for 30 min to remove oxygen prior to carry out the measurements. During the measurements a nitrogen atmosphere was maintained. Measurements were carried within the operational potential range of polyaniline $(-0.2$ $\mathrm{V},+0.875 \mathrm{~V}$ ) with a scan rate of $50 \mathrm{mV} \mathrm{s}^{-1}$. Different experiments were carried out to determine the redox behavior of the dyes:

- Characterization of the dyes on bare Pt electrodes:

o Observe the behavior of the dyes on Pt and determine its different redox processes.

o Determine if the species generated are adsorbed on the surface of the electrode or are generated in the vicinity of the electrode.

- Characterization of the dyes on Pt-Pani-Pt electrodes:

○ Observe if the redox processes of the dyes observed on bare Pt appear on Pt-Pani-Pt electrodes.

o Determine the dependence of the intensity of the redox bands with the $\mathrm{Pt}$ $\operatorname{load}\left(\mu \mathrm{g} \mathrm{cm}^{-2}\right)$.

o Determine the dependence of the bands intensity with the scan rate employed $\left(\mathrm{mV} \mathrm{s}^{-1}\right)$.

\section{Results and discussion}

3.1. Characterization of the employed electrodes

3.1.1. Scanning electron microscopy (SEM) 
The amount of $\mathrm{Pt}\left(\mu \mathrm{g} \mathrm{cm} \mathrm{cm}^{-2}\right)$ was calculated by the synthesis charge $\left.(\mathrm{mC} \mathrm{cm})^{-2}\right)$ (measured by the potentiostat/galvanostat) assuming that the only process that takes place is the reduction of $\mathrm{PtCl}_{6}{ }^{2-}$ to $\mathrm{Pt}$ with $100 \%$ efficiency [16]. The quantity of $\mathrm{Pt}$ $\left(\mathrm{m}_{\mathrm{Pt}}\right)$ was calculated according to Equation 1:

$$
m_{P t}=\frac{Q_{P t} \cdot M}{4 \cdot F}
$$

Where: $\mathrm{Q}_{\mathrm{Pt}}$ is the synthesis charge $\left(\mathrm{C} \mathrm{cm}^{-2}\right) ; \mathrm{M}$ is the $\mathrm{Pt}$ atomic weight $\left(195.09 \mathrm{~g} \mathrm{~mol}^{-1}\right)$; 4 is the number of electrons involved in the reduction of $\mathrm{PtCl}_{6}{ }^{2-}$ to $\mathrm{Pt}$ and $\mathrm{F}$ is the Faraday constant $\left(96485.3 \mathrm{C} \mathrm{mol}^{-1}\right)$. The load of Pt for the synthesis charges of 300 , 600, 900 and $1200 \mathrm{mC} \mathrm{cm}^{-2}$ was approximately $150,300,450$ and $600 \mu \mathrm{g} \mathrm{cm}^{-2}$, respectively.

Scanning electron microscopy (SEM) was employed to observe the morphology of the coatings obtained and also the Pt nanoparticles distribution. Polyaniline coating on $\mathrm{Pt}$ was very smooth and morphological features could not be observed (figure not shown). Fig. 2 shows micrographs of Pt-Pani-Pt electrodes obtained with different Pt loads $(\mu \mathrm{g}$ $\left.\mathrm{cm}^{-2}\right)$. Fig. 2-a shows a micrograph with the lower Pt load $\left(150 \mu \mathrm{g} \mathrm{cm}^{-2}\right)$. In this micrograph the presence of a continuous distribution of globular Pt nanoparticles can be observed. Their distribution is quite uniform and they are well dispersed on the polyaniline layer since they are not aggregated. Fig. 2-b shows the micrograph of a sample with a Pt load of $300 \mu \mathrm{g} \mathrm{cm}{ }^{-2}$. We can observe that Pt nanoparticles almost cover the entire surface of the electrode and they are joined creating a continuous layer of Pt nanoparticles. The size of the Pt nanoparticles is almost the same than with $150 \mu \mathrm{g}$ $\mathrm{cm}^{-2}$. With higher Pt loads $\left(450 \mu \mathrm{g} \mathrm{cm}^{-2}\right)$ it can be seen the growth of the Pt nanoparticles size (Fig. 2-c). Finally, with the highest Pt load $\left(600 \mu \mathrm{g} \mathrm{cm}^{-2}\right)$ it can be seen the growth of the nanoparticles size as well as the apparition of cracks on the coating (Fig. 2-d). These cracks will create peeling of the coating during its 
employment, so such a high Pt load does not improve the coating properties. Analyzing the micrographs, $300 \mu \mathrm{g} \mathrm{cm}^{-2}$ would be the optimum Pt load since it has a uniform distribution of Pt nanoparticles with low size of the Pt nanoparticles.

X-ray photoelectron spectroscopy measurements (XPS) were also carried out to certify that the nanoparticles observed were due to the deposition of Pt and also determine the oxidation state of the different elements (section 3.1.3).

\subsubsection{Atomic force microscopy measurements (AFM)}

Scanning electron microscopy (SEM) has not sufficient vertical resolution to appreciate variations of the topography at the nanometer scale. For this reason, atomic force microscopy (AFM) measurements were employed [27,28]. In addition, AFM has the advantage that no material is added to coat the samples. In SEM, samples are coated with $\mathrm{Au}$ or $\mathrm{C}$. Atomic force microscopy (AFM) measurements were done to obtain the 2-D and 3-D representations of the topography of the coatings and evaluate its variation as well as the roughness. 2-D and 3-D representations of $5 \mu \mathrm{m} \times 5 \mu \mathrm{m}$ were obtained. Topographic profiles for each sample were also obtained and compared. Fig. 3-a,b,c,d,e compare the 2-D representations of the different electrodes prior and after the deposition with the different Pt loads. The topographic profiles of the different images (shown in Fig. 3-f) have been also marked in the 2-D representations with different colors. The surface of the $\mathrm{Pt}$ wire coated with polyaniline is quite smooth with no mentionable topographical features (Fig. 3-a). The root-mean-squared roughness (Rrms) obtained for this sample was $44 \mathrm{~nm}$. The topographic profile obtained (blue line) showed no mentionable features since it was quite smooth. However, after deposition with the

lowest Pt load $\left(150 \mu \mathrm{g} \mathrm{cm}^{-2}\right)$, the apparition of different nanoparticles can be seen in Fig. 5-b. The growth of individual Pt nanoparticles on the Pani coating can be observed 
on the left side of the image. The roughness obtained for this image was $113 \mathrm{~nm}$. The topographic profile obtained (green line) showed the apparition of different peaks due to the groth of Pt nanoparticles. The sample coated with a Pt load of $300 \mu \mathrm{g} \mathrm{cm}^{-2}$ can be seen in Fig. 5-c. In this figure we can observe that the entire surface of the electrode is coated with Pt nanoparticles. The roughness obtained was $95.5 \mathrm{~nm}$. The topographic profile obtained (red line) showed the apparition of different peaks due to the $\mathrm{Pt}$ nanoparticles formation. In this case, the height of the Pt nanoparticles increased slightly comparing it with the latter one. A higher increase in the Pt load produces the vertical growth of the coating as well as the increase of the size of the Pt nanoparticles. Fig. 5-d and Fig. 5-e show the 2-D representations of the electrodes coated with the Pt loads of $450 \mu \mathrm{g} \mathrm{cm}^{-2}$ and $600 \mu \mathrm{g} \mathrm{cm}^{-2}$; Rrms also increased till $135 \mathrm{~nm}$ and $232 \mathrm{~nm}$, respectively. This vertical growth of the Pt nanoparticles can also be observed in the topographic profiles (purple and black lines for $450 \mu \mathrm{g} \mathrm{cm}$ and $600 \mu \mathrm{g} \mathrm{cm}$, respectively), where a significant increase of the height of the coating can be seen. The increase of the nanoparticles size can also be clearly observed.

\subsubsection{X-ray photoelectron spectroscopy measurements (XPS)}

X-ray photoelectron spectroscopy (XPS) technique was employed to determine the composition as well as the oxidation state of the elements present in the samples. Pt electrodes coated with Pani and dispersed Pt electrodes (Pt-Pani-Pt $300 \mu \mathrm{g} \mathrm{cm}^{-2}$ ) were analyzed by XPS. C1s, O1s, S2p, N1s, Pt4f and Cl2p core levels spectra were analyzed. Table 1 shows the most important XPS assignments to a better understanding of the text.

Fig. 4-a shows the high resolution C1s spectrum for a Pt-Pani-Pt sample. Three different contributions at $284.5 \mathrm{eV}, 286.2 \mathrm{eV}$ and $288.0 \mathrm{eV}$ were observed. The peak at $284.5 \mathrm{eV}$ 
was assigned to C-C groups [29]. The peak at $286.2 \mathrm{eV}$ was ascribed to $\mathrm{C}-\mathrm{N}, \mathrm{C}=\mathrm{N}, \mathrm{C}-\mathrm{O}$ and $\mathrm{C}-\mathrm{OH}$ groups [30,31]. The highest binding energy peak was located at $288.0 \mathrm{eV}$ and corresponded to $\mathrm{C}-\mathrm{N}^{+}, \mathrm{C}=\mathrm{N}^{+}$and $\mathrm{C}=\mathrm{O}$ groups [29].

Fig. 4-b shows the high resolution O1s spectrum for the Pt-Pani-Pt specimen. The O1s core level peak was deconvoluted in three contributions centered at $531.1 \mathrm{eV}, 532.4 \mathrm{eV}$ and $533.7 \mathrm{eV}$. The peak at $531.1 \mathrm{eV}$ was caused by $\mathrm{HSO}_{4}{ }^{-}$and $\mathrm{SO}_{4}{ }^{2-}$ groups from the counter ion [32]. The peak at $532.4 \mathrm{eV}$ was due to $\mathrm{C}-\mathrm{OH}$ and $\mathrm{C}-\mathrm{O}$ groups $[31,33]$. The peak at $533.7 \mathrm{eV}$ was attributed to $\mathrm{C}=\mathrm{O}$ group [30-33].

Fig. 4-c shows the high resolution N1s XPS spectrum for the Pt-Pani sample. The signal obtained was deconvoluted into three contributions centered at $397.9 \mathrm{eV}, 399.8 \mathrm{eV}$ and $401.9 \mathrm{eV}$. The peak at $397.9 \mathrm{eV}$ was due to neutral quinonoid imine group $(-\mathrm{N}=)$ [30]. The peak at $399.8 \mathrm{eV}$ was assigned to neutral amine-like (-NH-) structure $[29,33]$. The peak at $401.9 \mathrm{eV}$ was ascribed to charged protonated quinonoid imine $\left(-\mathrm{NH}^{+}=\right)$[29]. The doping ratio obtained $\left(-\mathrm{NH}^{+}=/ \mathrm{N}_{\text {Total }}\right)$ was 0.27 (about 1 charged imine for each 4 benzenoid-quinonoid rings).

The high resolution Pt4f spectrum is shown in Fig. 4-d. Four deconvoluted peaks appeared in this spectrum. The two peaks at $71.4 \mathrm{eV}\left(\mathrm{Pt}_{4 / 2}\right)$ and $74.6 \mathrm{eV}\left(\mathrm{Pt}_{7 \mathrm{f}_{5 / 2}}\right)$ were assigned to a spin-orbit coupling doublet. The doublet separation of $3.2 \mathrm{eV}$ is characteristic of platinum element (Pt4f) [32]. These binding energies were due to metallic Pt [31]. Other doublet was obtained at $73.0 \mathrm{eV}$ and $76.2 \mathrm{eV}$. This doublet was assigned to $\mathrm{Pt}^{2+}$ [34]. About $14 \%$ (atomic) of the total $\mathrm{Pt}^{4+}$, from $\mathrm{H}_{2} \mathrm{PtCl}_{6}$, was not completely reduced to metallic Pt. The metallic Pt atomic content obtained by XPS measurements was $18.6 \%$ (75\% by mass).

\subsubsection{Cyclic voltammetry (CV)}


The redox behavior of Pani is highly affected by pH [35]. In Fig. 5 the voltammograms of a Pt-Pani electrode in pHs 0.3, 2.3 are shown. At these pHs, Pani coating shows similar degree of electroactivity, however a displacement of the potential of the redox processes has been observed. The voltammogram of Pani in a solution of $\mathrm{pH} 5.4$ is also shown in Fig. 5. In this $\mathrm{pH}$, Pani shows a non conductive behaviour due to its complete deprotonation that occurs at $\mathrm{pH}>4$ [36]. In acid $\mathrm{pHs}$ such as 0.3 and 2.3, it would not be possible to discern the different contributions (from $\mathrm{Pt}$ and Pani) of the electroactivity measured by SECM. So the $\mathrm{pH}$ of 5.4 would be an adequate $\mathrm{pH}$ to carry out SECM measurements since only $\mathrm{Pt}$ would contribute to the electroactivity measured.

\subsubsection{Scanning electrochemical microscopy (SECM). Feedback currents at UME tip} Scanning electrochemical microscopy (SECM) allows zonal analysis of electroactivity without polarizing the sample to study. Approach curves give an indication of the electroactivity of the electrode surface. If the surface is non conductive, when the electrode approaches the surface there is a decrease of the current measured (negative feedback) [23]. On the other hand, if the electrode is conductive, when the electrode approaches the surface of the substrate the current increases (positive feedback) [23]. In this part of the results, we compare the experimental approach curves obtained for the electrodes of study with the theoretical curves described in the SECM theory. Approach curves represent the variation of the normalized current $\left(\mathrm{I}_{\mathrm{T}}\right)$ with the normalized distance (L). The normalized currents are defined as: $\mathrm{I}_{\mathrm{T}}(\mathrm{L})=\mathrm{i} / \mathrm{i}_{\infty}$; where $\mathrm{i}_{\infty}=4 \cdot \mathrm{n} \cdot \mathrm{F} \cdot \mathrm{D} \cdot \mathrm{a} \cdot \mathrm{C}$ in which: $\mathrm{n}$ is the number of electrons involved in the reaction; $\mathrm{F}$ is the Faraday constant; $\mathrm{D}$ is the diffusion coefficient; $\mathrm{a}$ is the radius of the ultra-microelectrode (UME) and $\mathrm{C}$ is the concentration of the reactant. The normalized current depends on 
$\mathrm{RG}\left(\mathrm{RG}=\mathrm{R}_{\mathrm{g}} / \mathrm{a}\right.$, where $\mathrm{R}_{\mathrm{g}}$ is the radius of the insulating glass surrounding the tip of radius "a") and the normalized distance $L$ where $L=d / a(d$ is the UME-substrate separation). The RG of our UME tip is $R G \geq 20$. According to Rajendran et al. [37], Pade's approximation gives a close and simple equation with less relative error for all distances and valid for $R G>10$. The approximate expression of the steady-state normalized current assuming positive feedback for a glass finite insulator thickness is:

$$
I_{T}{ }^{C}=\left[\frac{1+1.5647 / L^{+1.316855} / L^{2}+0.4919707 / L^{3}}{1+1.1234 / L^{+0.626395 / L^{2}}}\right]
$$

The selection of the expression for the normalized tip current assuming negative feedback was based on the equation [38] for a $R G=20$ and $L$ range $(0.4-20)$.

$$
I_{T}{ }^{I N S}=\left[\frac{1}{0.3554+2.0259 / L+0.62832 \times \exp (-2.55622 / L)}\right]
$$

The approach $\left(\mathrm{I}_{\mathrm{T}}-\mathrm{L}\right)$ curves obtained for a Pt-Pani substrate in a $10 \mathrm{mM} \mathrm{Ru}\left(\mathrm{NH}_{3}\right)_{6} \mathrm{Cl}_{3}$ and $0.1 \mathrm{M} \mathrm{Na}_{2} \mathrm{SO}_{4}$ solution of $\mathrm{pH} 2.3$ are shown in Fig. 6. The curves were obtained with the substrate potential $\left(\mathrm{E}_{\mathrm{s}}\right)$ set to $+0.2 \mathrm{~V}$ and $+0.6 \mathrm{~V}$. The choice of $\mathrm{E}_{\mathrm{s}}$ potentials was done taking into account the Pt-Pani voltammogram (Fig. 5). At $+0.2 \mathrm{~V}$ and +0.6 $\mathrm{V}$ two redox peaks appear. The tip potential was set to $-0.3 \mathrm{~V}$. This potential was selected to reduce the oxidized form of the mediator, $\mathrm{Ru}\left(\mathrm{NH}_{3}\right)_{6}{ }^{3+}$, at a diffusioncontrolled rate (figure not shown).

A very good agreement between the theoretical and the experimental $\mathrm{I}_{\mathrm{T}}-\mathrm{L}$ curves could be observed. The behavior of Pt-Pani at pH 2.3 adjusted to the positive feedback model (Equation 2), so the conducting polymer behaves like a conducting material. At this $\mathrm{pH}$ Pani is in its protonated (conducting) form [36]. On the other hand, at $\mathrm{pH} 5.4$ the Pani became an insulator and the approach curve shows negative feedback, adjusting in this case to the negative feedback model (Equation 3). 
As previously commented, it was difficult to distinguish between the electrochemical behavior of Pt deposited pontentiostatically and the behavior of the Pani film of the substrate when $\mathrm{pH}$ is 2.3. At $\mathrm{pH} 5.4$ the contribution of Pani is removed since it is non conductive at this $\mathrm{pH}$. Therefore, $\mathrm{pH} 5.4$ was selected to carry out the measurements with the samples containing dispersed Pt since only Pt contributes to the electroactivity measured at this $\mathrm{pH}$. In this case, approach $\mathrm{I}_{\mathrm{T}}-\mathrm{L}$ curves, were obtained with the system at its open circuit potential mode $(\mathrm{OCP})$ of $+0.3 \mathrm{~V}$. Fig. 7 , shows different approach curves obtained for the Pt-Pani-Pt electrode $\left(300 \mu \mathrm{g} \mathrm{cm}^{-2}\right)$. Approach curves show positive feedback in agreement with the theoretical model of positive feedback (for values of $\mathrm{L} \geq 0.6$ ), that is to say, for an UME distance from the substrate of approximately $7 \mu \mathrm{m}$. Very little variations in the approach curves were observed for repeated approaches to different locations.

\subsection{Characterization of amaranth and PMX2R on Pt electrodes}

Solutions of both dyes (amaranth and PMX2R) were previously characterized on $\mathrm{Pt}$ electrodes to observe and determine the different redox processes of the dyes. Fig. 8-a shows the electrochemical characterization of PMX2R $\left(4 \mathrm{~g} \mathrm{~L}^{-1}\right)$ and $0.5 \mathrm{M} \mathrm{H}_{2} \mathrm{SO}_{4}$ aqueous solution on Pt. The first scan was done after being $100 \mathrm{~s}$ at the reduction potential of $-0.2 \mathrm{~V}$. It can be clearly seen the apparition of an oxidation peak at a potential of $+0.44 \mathrm{~V}$ and a reduction peak at a potential of $+0.33 \mathrm{~V}$; the oxidation potential has a major intensity than the reduction one. The presence of a reduction wave for potentials $<0 \mathrm{~V}$ is also noticeable; in this wave contributions from $\mathrm{H}_{2}$ and dye processes can be expected. Then the second scan was performed and it can be seen that the intensity of both redox peaks decreased. Before the third scan, the potential was maintained at $-0.2 \mathrm{~V}$ during $100 \mathrm{~s}$; it can be seen that the current density increased until 
the values reached in the first scan. This indicates that the reduction wave observed for potentials $<0 \mathrm{~V}$ is in direct relation to the oxidation peak observed at $+0.44 \mathrm{~V}$. An accumulation time at $-0.2 \mathrm{~V}$ caused the generation of a major concentration of reduced species that are oxidized later at $+0.44 \mathrm{~V}$. The forth scan was done maintaining the potential of $-0.2 \mathrm{~V}$ during $100 \mathrm{~s}$ and after this, $\mathrm{N}_{2}$ gas was bubbled. It can be seen a great decrease of the redox processes of the dye (almost disappeared). This indicates that the species are generated in the vicinity of the electrode and are not adsorbed on the electrode surface. When $\mathrm{N}_{2}$ is bubbled, the dye species are removed from the surface of the Pt electrode. The species generated are not irreversibly adsorbed on the surface of the Pt electrode and they do not block the electrode. The fifth scan was performed without stirring and it can be seen that the intensity of both peaks increased slightly after being practically removed in the fourth scan.

An additional experiment was performed to show that there is a direct relationship between the reduction wave at $<0 \mathrm{~V}$ and the oxidation peak observed at $+0.44 \mathrm{~V}$. Different scans were performed with the Pt electrode; however, in this case the reduction potential range was progressively varied from $-0.2 \mathrm{~V}$ to $-0.15 \mathrm{~V},-0.10 \mathrm{~V}$, $0.05 \mathrm{~V}$ and $0 \mathrm{~V}$ for the different scans performed. As it is shown in Fig. 9-a, the current density of the oxidation peak at $+0.44 \mathrm{~V}$ diminishes with the diminishing potential range, confirming that the oxidation peak appears due to the species generated during the reduction of the dye. Also the intensity of reduction peak at $+0.33 \mathrm{~V}$ is affected as we can see in this figure. The zone of the oxidation and reduction peaks has been magnified in Fig. 9-b for better observation of this dependence. The same behavior was also observed in the case of amaranth (figure not shown).

The characterization of amaranth on Pt electrodes showed similar results to that obtained for PMX2R (Fig. 8-b). The first scan was done after being $100 \mathrm{~s}$ at the 
reduction potential of $-0.2 \mathrm{~V}$. It can be clearly seen the apparition of an oxidation peak at a potential of $+0.47 \mathrm{~V}$ and a reduction peak at a potential of $+0.2 \mathrm{~V}$; the oxidation peak has a major intensity than the reduction one. In this case, the presence of a reduction wave for potentials $<0 \mathrm{~V}$ was also noticeable. The next scans $\left(2^{\text {nd }}\right.$ to $\left.5^{\text {th }}\right)$ were performed as that for PMX2R and the same behavior was observed:

- The species generated during the reduction process at $-0.2 \mathrm{~V}$ are oxidized later on the surface of the Pt electrode.

- The time of reduction at $-0.2 \mathrm{~V}$ increases the intensity of the redox peaks observed.

- The species generated on the surface of the electrode are not irreversible adsorbed on its surface and can be removed by stirring.

\subsection{Characterization of amaranth and PMX2R on Pt-Pani-Pt electrodes}

After determining the behavior of the dyes on electrodes of bare $\mathrm{Pt}$, the characterization was performed in the same conditions on electrodes of Pt-Pani-Pt. Different Pt loads were obtained $\left(\mu \mathrm{g} \mathrm{cm}^{-2}\right)$ by controlling the deposition charge $\left(\mathrm{mC} \mathrm{cm}^{-2}\right)$. The Pt loads obtained were $150,300,450$, and $600 \mu \mathrm{g} \mathrm{cm}{ }^{-2}$. Analyzing the results obtained on $\mathrm{Pt}$ electrodes, we could see that the second scan is the stabilized scan, since the accumulation time at $-0.2 \mathrm{~V}$ of the first scan causes an increase of the current peaks. This is why in the next figures; the second scan will be presented instead of the first one.

Fig. 10 shows the different voltammograms of PMX2R (4 g L $\left.{ }^{-1}\right)$ (Fig. 10-a) and $3 \mathrm{~g} \mathrm{~L}^{-1}$ amaranth (Fig. 10-b) in $0.5 \mathrm{M} \mathrm{H}_{2} \mathrm{SO}_{4}$ aqueous solutions on the different Pt-Pani-Pt electrodes obtained. The voltammograms obtained on bare Pt electrodes have been also included for comparison. In the voltammograms, the characteristic oxidation and 
reduction processes on $\mathrm{Pt}$ are overlapped with that of the dyes. However, the presence of the oxidation peaks of the dyes at $+0.44 \mathrm{~V}(\mathrm{PMX} 2 \mathrm{R})$ and $+0.47 \mathrm{~V}$ (amaranth) is clearly observed in the corresponding voltammograms. It can also be seen that as the $\mathrm{Pt}$ load increases, the intensity of the peak also increases, due to a higher active area. The increase in the intensity of the oxidation peak can be better observed in the case of amaranth (Fig. 10-b). However, this increase was not very significant from a Pt load of 300 to $600 \mu \mathrm{g} \mathrm{cm}^{-2}$. The optimum load obtained in SEM and AFM measurements was $300 \mu \mathrm{g} \mathrm{cm}^{-2}$, so this Pt load was selected to perform further experiments. Higher Pt loads do not produce a significant improvement and can even lead to cracks in the coating as it was observed by means of SEM (Fig. 2-d).

The same experiments carried out with bare Pt (Fig. 8) were done with the electrodes with dispersed Pt. The same behavior obtained with bare Pt was observed: the species are generated by reduction in the vicinity of the electrode and are not adsorbed on the electrode surface (figure not shown) since after stirring the different redox processes disappeared. An accumulation time at $-0.2 \mathrm{~V}$ caused the increase of the redox peaks.

Fig. 11 shows a comparison between the voltammograms of the Pt-Pani-Pt $\left(300 \mu \mathrm{g} \mathrm{cm}^{-}\right.$ ${ }^{2}$ ) electrode in the blank $\left(0.5 \mathrm{M} \mathrm{H}_{2} \mathrm{SO}_{4}\right)$ and in the dye solutions $\left(4 \mathrm{~g} \mathrm{~L}^{-1} \mathrm{PMX} 2 \mathrm{R}\right.$ or $3 \mathrm{~g}$ $\mathrm{L}^{-1}$ amaranth and $0.5 \mathrm{M} \mathrm{H}_{2} \mathrm{SO}_{4}$ ). The characterization of bare $\mathrm{Pt}$ in the dye solutions has been also included for comparison.

Fig. 11-a shows the comparison for PMX2R. In the voltammogram of the Pt-Pani-Pt electrode in the blank solution, the characteristic oxidation and reduction processes on Pt surface can be observed at potentials $<+0.1 \mathrm{~V}$ and potentials $>+0.5 \mathrm{~V}$, respectively [39]. The characterization of the electrode in the dye solution showed the clear current density diminution of the characteristic $\mathrm{Pt}$ response at potentials $>+0.5 \mathrm{~V}$. As previously commented, an oxidation peak of the PMX2R dye appeared at $+0.44 \mathrm{~V}$. The 
reduction of the dye can also be observed since an increase of the reduction current compared to the blank solution occurs at potentials $<0 \mathrm{~V}$, although this process is overlapped with reduction processes, characteristic of Pt electrodes.

The characterization of amaranth showed similar behavior to that obtained for PMX2R (Fig. 11-b). The characteristic oxidation and reduction processes at $>0.5 \mathrm{~V}$ on $\mathrm{Pt}$ also showed a diminution of its current density, however in this case the diminution was lower than in the PMX2R case. The appearance of the oxidation peak of amaranth can be observed at $+0.47 \mathrm{~V}$. For potentials $<0 \mathrm{~V}$ is also mentionable the rise of the reduction current density due to the contribution of the dye reduction processes, although its contribution is also mixed with that of reduction processes characteristic of Pt electrodes.

The dependence of the current density of the redox peaks with the scan rate gives information about the reaction mechanism. Fig. 12 shows the voltammograms obtained for the Pt-Pani-Pt electrode $\left(300 \mu \mathrm{g} \mathrm{cm}^{-2}\right)$ in the dye solutions employing different scan rates $\left(50,100,150,200,250,300,350,400,450\right.$ and $\left.500 \mathrm{mV} \mathrm{s}^{-1}\right)$. Fig. 12-a, shows the voltammograms of PMX2R and Fig. 12-b the voltammograms of amaranth.

In the voltammograms it can be seen that the rise of the scan rate, causes an increase of the current density of the different processes observed in the voltammograms. The oxidation processes of PMX2R and amaranth can be observed at $+0.44 \mathrm{~V}$ and $+0.47 \mathrm{~V}$, respectively. The intensity of these oxidation peaks was represented vs. the square root of the scan rate (Fig. 13). The straight line in the plot of $I_{p} v s . v^{1 / 2}$ indicates that the oxidation process for both dyes is a diffusion controlled process. 


\section{Conclusions}

Electrodes of Pt have been coated with polyaniline and later with dispersed Pt. Different Pt loads $\left(\mu \mathrm{g} \mathrm{cm}^{-2}\right)$ have been obtained by controlling the synthesis charge $\left(\mathrm{mC} \mathrm{cm}^{-2}\right)$. Scanning electron microscopy (SEM) and atomic force microscopy (AFM) measurements showed that the optimum load was $300 \mu \mathrm{g} \mathrm{cm}^{-2}$ since higher charges produce the increase of the nanoparticles size and even the presence of cracks in the coatings. X-ray photoelectron spectroscopy measurements showed the formation of a metallic Pt layer with a Pt content of $18.6 \%$ (atomic) and $75 \%$ (mass). Scanning electrochemical microscopy (SECM) allowed us to observe at scale of micrometers the electrochemical behavior of Pt-Pani and Pt-Pani-Pt electrodes with the $\mathrm{pH}$. At $\mathrm{pH}<4$ is not possible to separate the contributions to electroactivity of Pani and Pt. However at $\mathrm{pH}>4$, Pani suffers deprotonation and becomes non electroactive. So, the characterization at $\mathrm{pH} 5.4$ allowed the study of the electroactivity of the Pt nanoparticles since Pani was non electroactive at this $\mathrm{pH}$.

The electrochemical characterization of procion orange MX-2R (PMX2R) and amaranth has been performed by cyclic voltammetry. Their electrochemical behaviour has been performed on electrodes of bare Pt and electrodes of Pt coated with polyaniline and dispersed Pt (Pt-Pani-Pt). The voltammetric characterization of both dyes on $\mathrm{Pt}$ electrodes has shown that both dyes present different oxidation and reduction processes. The most significant ones are the oxidation peaks that appear at $+0.44 \mathrm{~V}$ and $+0.47 \mathrm{~V}$ for PMX2R and amaranth respectively. It has been demonstrated that the species generated of the dyes are in the vicinity of the electrode and are not adsorbed on the surface of the electrode. An accumulation time at the reduction potential of $-0.2 \mathrm{~V}$ causes the increase of the oxidation peaks of the dyes. The characterization of the dyes on the electrodes with dispersed Pt showed similar behaviour to that obtained with bare 
Pt. The presence of the dyes also causes the diminution of the characteristic oxidation and reduction processes of Pt. Different scan rates were also employed and it was obtained that the oxidation processes $(+0.44 \mathrm{~V}$ and $+0.47 \mathrm{~V}$ for PMX2R and amaranth, respectively) are controlled by diffusion. The results obtained suggest that a combined electroreduction/electrooxidation treatment would be a good strategy for the electrochemical treatment of these azo dyes.

\section{Acknowledgements}

Authors thank to the Spanish Ministerio de Ciencia e Innovación and European Union Funds (FEDER) (contracts CTM2010-18842-C02-02 and CTM2011-23583) and Universitat Politècnica de València (Vicerrectorado de Investigación PAID-06-10 contract 003-233) for the financial support. J. Molina is grateful to the Conselleria d'Educació (Generalitat Valenciana) for the FPI fellowship. A.I. del Río is grateful to the Spanish Ministerio de Ciencia y Tecnología for the FPI fellowship.

\section{References}

[1] M.J. Croissant, T. Napporn, J.-M. Léger, C. Lamy, Electrocatalytic oxidation of hydrogen at platinum-modified polyaniline electrodes, Electrochim. Acta 43 (1998) $2447-2457$.

[2] X.-W. Liu, J.-J. Mao, P.-D. Liu, X.-W. Wei, Fabrication of metal-graphene hybrid materials by electroless deposition, Carbon 49 (2011) 477-483. 
[3] Z. Zhu, J. Wang, A. Munir, H.S. Zhou, Electrocatalytic activity of Pt nanoparticles on bamboo shaped carbon nanotubes for ethanol oxidation, Electrochim. Acta 55 (2010) $8517-8520$

[4] Z. Lin, L. Ji, X. Zhang, Electrodeposition of platinum nanoparticles onto carbon nanofibers for electrocatalytic oxidation of methanol, Mater. Lett. 63 (2009) 2115-2118. [5] F. Gloaguen, J.M. Léger, C. Lamy, A. Marmann, U. Stimming, R. Vogela, Platinum electrodeposition on graphite: electrochemical study and STM imaging, Electrochim. Acta 44 (1999) 1805-1816.

[6] G. Lu, G. Zangari, Electrodeposition of Platinum on Highly Oriented Pyrolytic Graphite. Part I: Electrochemical Characterization, J. Phys. Chem. B 109 (2005) 79988007.

[7] G. Lu, G. Zangari, Electrodeposition of platinum nanoparticles on highly oriented pyrolitic graphite: Part II: Morphological characterization by atomic force microscopy, Electrochim. Acta 51 (2006) 2531-2538.

[8] P. Yu, J. Yan, J. Zhang, L. Mao, Cost-effective electrodeposition of platinum nanoparticles with ionic liquid droplet confined onto electrode surface as micro-media, Electrochem. Commun. 9 (2007) 1139-1144.

[9] H.B. Hassan, Electrodeposited Pt and Pt-Sn nanoparticles on Ti as anodes for direct methanol fuel cells, J. Fuel Chem. Technol. 37 (2009) 346-354.

[10] L. Niu, Q. Li, F. Wei, X. Chen, H. Wang, Formation optimization of platinummodified polyaniline films for the electrocatalytic oxidation of methanol, Synth. Met. 139 (2003) 271-276.

[11] K. Bouzek, K.-M. Mangold, K. Jüttner, Electrocatalytic activity of platinum modified polypyrrole films for the methanol oxidation reactions, J. Appl. Electrochem. $31(2001) 501-507$. 
[12] L. Niu, Q. Li, F. Wei, S. Wu, P. Liu, X. Cao, Electrocatalytic behavior of Ptmodified polyaniline electrode for methanol oxidation: Effect of Pt deposition modes, J. Electroanal. Chem. 578 (2005) 331-337.

[13] J. Li, X. Lin, A composite of polypyrrole nanowire platinum modified electrode for oxygen reduction and methanol oxidation reactions, J. Electrochem. Soc. 154 (2007) B1074-B1079.

[14] H. Laborde, J.-M. Léger, C. Lamy, Electrocatalytic oxidation of methanol and C1 molecules on highly dispersed electrodes Part 1: Platinum in polyaniline, J. Appl. Electrochem. 24 (1994) 219-226.

[15] L. Li, Y. Zhang, J.-F. Drillet, R. Dittmeyer, K.-M. Jüttner, Preparation and characterization of $\mathrm{Pt}$ direct deposition on polypyrrole modified Nafion composite membranes for direct methanol fuel cell applications, Chem. Eng. J. 133 (2007) 113119.

[16] S. Domínguez-Domínguez, J. Arias-Pardilla, A. Berenguer-Murcia, E. Morallón, D. Cazorla-Amorós, Electrochemical deposition of platinum nanoparticles on different carbon supports and conducting polymers, J. Appl. Electrochem. 38 (2008) 259-268.

[17] C.A. Martínez-Huitle, E. Brillas, Decontamination of wastewaters containing synthetic organic dyes by electrochemical methods: A general review, Appl. Catal. BEnviron. 87 (2009) 105-145.

[18] M.C. Gutiérrez, M. Crespi, A review of electrochemical treatments for colour elimination, J. Soc. Dyers Colourists 115 (1999) 342-345.

[19] L. Fan, Y. Zhou, W. Yang, G. Chen, F. Yang, Electrochemical degradation of aqueous solution of Amaranth azo dye on ACF under potentiostatic model, Dyes Pigments 76 (2008) 440-446. 
[20] L. Fan, Y. Zhou, W. Yang, G. Chen, F. Yang, Electrochemical degradation of Amaranth aqueous solution on ACF, J. Hazard. Mater. 137 (2006) 1182-1188.

[21] M.P. Char, E. Niranjana, B.E.K. Swamy, B.S. Sherigara, K.V. Pai, Electrochemical studies of amaranth at surfactant modified carbon paste electrode: A Cyclic Voltammetry, Int. J. Electrochem. Sci. 3 (2008) 588-596

[22] A.I. del Río, J. Molina, J. Bonastre, F. Cases, Influence of electrochemical reduction and oxidation processes on the decolourisation and degradation of C.I. Reactive Orange 4 solutions, Chemosphere 75 (2009) 1329-1337.

[23] P. Sun, F.O. Laforge, M.V. Mirkin, Scanning electrochemical microscopy in the 21st century, Phys. Chem. Chem. Phys. 9 (2007) 802-823.

[24] M.V. Mirkin, B.R. Horrocks, Electroanalytical measurements using the scanning electrochemical microscope, Anal. Chim. Acta 406 (2000) 119-146.

[25] A.L. Barker, M. Gonsalves, J.V. Macpherson, C.J. Slevin, P.R. Unwin, Scanning electrochemical microscopy: beyond the solid/liquid interface, Anal. Chim. Acta 385 (1999) 223-240.

[26] J. Clavilier, The role of anion on the electrochemical behaviour of a $\{111\}$ platinum surface; an unusual splitting of the voltammogram in the hydrogen region, $\mathrm{J}$. Electroanal. Chem. 107 (1979) 211-216.

[27] K. Tammeveski, T. Tenno, J. Niinisto, T. Leitner, G. Friedbacher, L. Niinisto, Thermal preparation of thin platinum coatings and their electrochemical and atomic force microscopic characterization, Appl. Surf. Sci. 156 (2000) 135-142.

[28] H. Kikuchi, W. Ouchida, M. Nakamura, C. Goto, M. Yamada, N. Hoshi, Atomic force microscopy of cubic Pt nanoparticles in electrochemical environments, Electrochem. Commun. 12 (2010) 544-547. 
[29] M.G. Han, S.S. Im, X-ray photoelectron spectroscopy study of electrically conducting polyaniline/polyimide blends, Polymer 41 (2000) 3253-3262.

[30] R. Rajagopalan, J.O. Iroh, Characterization of polyaniline-polypyrrole composite coatings on low carbon steel: a XPS and infrared spectroscopy study, Appl. Surf. Sci. 218 (2003) 58-69.

[31] R. Benoit, Y. Durand, B. Narjoux, G. Quintana, X-ray photoelectron spectroscopy database. La Surface, CNRS and Thermo Fisher Scientific, Thermo Electron France. Available from: http://www.lasurface.com/database/elementxps.php. (last accessed 11.30.11)

[32] C.D. Wagner, A.V. Naumkin, A. Kraut-Vass, J.W. Allison, C.J. Powell, J.R. Rumble Jr., NIST X-ray photoelectron spectroscopy database, The National Institute of Standards and Technology, U.S. Department of Commerce, 2007, Available from: http://srdata.nist.gov/xps/Default.aspx (last accessed 11.30.11).

[33] A.P. Monkman, G.C. Stevens, D. Bloor, X-ray photoelectron spectroscopic investigations of the chain structure and doping mechanisms in polyaniline, J. Phys. D: Appl. Phys. 24 (1991) 738-749.

[34] A. Drelinkiewicz, A. Zięba, J.W. Sobczak, M. Bonarowska, Z. Karpiński, A. Waksmundzka-Góra, J. Stejskal, Polyaniline stabilized highly dispersed Pt nanoparticles: Preparation, characterization and catalytic properties, React. Funct. Polym. 69 (2009) 630-642.

[35] E. Salamifar, M.A. Mehrgardi, M.F. Mousavi, Ion transport and degradation studies of a polyaniline-modified electrode using SECM, Electrochim. Acta 54 (2009) 4638-4646.

[36] A.G. MacDiarmid, Synthetic metals: a novel role for organic polymers, Synth. Met. 125 (2002) 11-22. 
[37] L. Rajendran, S.P. Ananthi, Analysis of positive feedback currents at the scanning electrochemical microscope, J. Electroanal. Chem. 561 (2004) 113-118.

[38] A.J. Bard, M.V. Mirkin, Scanning Electrochemical Microscopy, Marcel Dekker, Inc., New York, 2001.

[39] J. Wang, Analytical electrochemistry, second ed., Wiley-VCH, New York, 2000.

\section{Figure captions}

Fig. 1. Molecular structures of: a) procion orange MX-2R, b) amaranth.

Fig. 2. SEM micrographs of Pt-Pani-Pt electrodes with different Pt loads: a) $150 \mu \mathrm{g} \mathrm{cm}^{-}$ ${ }^{2}$, b) $300 \mu \mathrm{g} \mathrm{cm}^{-2}$, c) $450 \mu \mathrm{g} \mathrm{cm}{ }^{-2}$, d) $600 \mu \mathrm{g} \mathrm{cm}^{-2}$; magnification (x4000).

Fig. 3. AFM 2D topographic representations of: a) Pt-Pani, b) Pt-Pani-Pt $150 \mu \mathrm{g} \mathrm{cm}^{-2}$, c) Pt-Pani-Pt $300 \mu \mathrm{g} \mathrm{cm}^{-2}$, d) Pt-Pani-Pt $450 \mu \mathrm{g} \mathrm{cm}^{-2}$, e) Pt-Pani-Pt $600 \mu \mathrm{g} \mathrm{cm}^{-2}$.

Fig. 4. $\mathrm{C}_{1 \mathrm{~s}}(\mathrm{a}), \mathrm{O}_{1 \mathrm{~s}}(\mathrm{~b}), \mathrm{N} 1 \mathrm{~s}$ (c) and Pt4f (d) XPS high resolution spectra for Pt-Pani-Pt $\left(300 \mu \mathrm{g} \mathrm{cm}^{-2}\right)$.

Fig. 5. Cyclic voltammograms of a Pt-Pani electrode in a solution of $\mathrm{pH} 0.3,2.3$ and 5.4 in $0.1 \mathrm{M} \mathrm{Na}_{2} \mathrm{SO}_{4}$. Scan rate rate, $50 \mathrm{mV} \mathrm{s}^{-1}$.

Fig. 6. Normalized steady-state current curves for a Pt tip approaching Pt-Pani electrode in $0.01 \mathrm{M} \mathrm{Ru}\left(\mathrm{NH}_{3}\right)_{6}{ }^{3+}$ and $0.1 \mathrm{M} \mathrm{Na}_{2} \mathrm{SO}_{4}$ solution of $\mathrm{pH}$ 2.3. Pt-Pani electrode was 
biased at $+0.6 \mathrm{~V}(\diamond)$ and $+0.2 \mathrm{~V}(\Delta)$. For the non conductive Pt-Pani at $\mathrm{pH} 5.4$ the substrate potential was $+0.6 \mathrm{~V}(-)$. Thick solid curves (-) represent the theoretical positive and negative feedback models. UME tip moved at $10 \mu \mathrm{m} \mathrm{s}^{-1}$.

Fig. 7. Normalized steady-state current curves for a Pt tip approaching Pt-Pani-Pt (300 $\mu \mathrm{g} \mathrm{cm}^{-2}$ ) in $0.01 \mathrm{M} \mathrm{Ru}\left(\mathrm{NH}_{3}\right)_{6}{ }^{3+}$ and $0.1 \mathrm{M} \mathrm{Na}_{2} \mathrm{SO}_{4}$ solution of $\mathrm{pH} 5.4$ (ם). The substrate potential was $+0.3 \mathrm{~V}$. Thick solid curve (-) represents the theoretical positive feedback model. UME tip moved at $10 \mu \mathrm{m} \mathrm{s}^{-1}$.

Fig. 8. Cyclic voltammograms of aqueous solutions of (a) PMX2R (4 g L $\left.{ }^{-1}\right)$ and, (b) amaranth $\left(3 \mathrm{~g} \mathrm{~L}^{-1}\right)$ in $0.5 \mathrm{M} \mathrm{H}_{2} \mathrm{SO}_{4}$. Pt working electrode; scan rate $50 \mathrm{mV} \mathrm{s}^{-1}$; range potential $(-0.2 \mathrm{~V},+0.875 \mathrm{~V}) \cdot 1^{\text {st }}$ scan $(100 \mathrm{~s}$ at $-0.2 \mathrm{~V}) ; 2^{\text {nd }}$ scan (normal); $3^{\text {rd }}$ scan $(100 \mathrm{~s}$ at $-0.2 \mathrm{~V}) ; 4^{\text {th }} \mathrm{scan}\left(100 \mathrm{~s}\right.$ at $-0.2 \mathrm{~V}$ and bubbling $\left.\mathrm{N}_{2}\right) ; 5^{\text {th }}$ scan (normal).

Fig. 9. Cyclic voltammograms of aqueous solutions of (a) PMX2R $\left(4 \mathrm{~g} \mathrm{~L}^{-1}\right)$ in $0.5 \mathrm{M}$ $\mathrm{H}_{2} \mathrm{SO}_{4}$. Pt working electrode; scan rate $50 \mathrm{mV} \mathrm{s}^{-1}$; range potentials $(-0.2 \mathrm{~V},+0.875 \mathrm{~V})$; $(-0.15 \mathrm{~V},+0.875 \mathrm{~V}) ;(-0.10 \mathrm{~V},+0.875 \mathrm{~V}) ;(-0.05 \mathrm{~V},+0.875 \mathrm{~V}) ;(0 \mathrm{~V},+0.875 \mathrm{~V})$ First scan for all measurements.

Fig. 10. Cyclic voltammograms of aqueous solutions of (a) PMX2R (4 g L $\left.{ }^{-1}\right)$ and, (b) amaranth $\left(3 \mathrm{~g} \mathrm{~L}^{-1}\right)$ in $0.5 \mathrm{M} \mathrm{H}_{2} \mathrm{SO}_{4}$. Pt and Pt-Pani-Pt (150, 300, 450 and $\left.600 \mu \mathrm{g} \mathrm{cm}^{-2}\right)$ working electrodes. Scan rate $50 \mathrm{mV} \mathrm{s}^{-1}$; range potential $(-0.2 \mathrm{~V},+0.875 \mathrm{~V})$; second scan for all samples. 
Fig. 11. Voltammograms of the Pt-Pani-Pt $\left(300 \mu \mathrm{g} \mathrm{cm}^{-2}\right)$ electrode in the blank $(0.5 \mathrm{M}$ $\left.\mathrm{H}_{2} \mathrm{SO}_{4}\right)$ and in the dye solutions $\left(4 \mathrm{~g} \mathrm{~L}^{-1} \mathrm{PMX} 2 \mathrm{R}\right.$ or $3 \mathrm{~g} \mathrm{~L}^{-1}$ amaranth and $\left.0.5 \mathrm{M} \mathrm{H}_{2} \mathrm{SO}_{4}\right)$. PMX2R (Fig. 9-a) and amaranth (Fig. 9-b). Pt characterization in the dye solutions has been also included for comparison. Scan rate $50 \mathrm{mV} \mathrm{s}^{-1}$; range potential $(-0.2 \mathrm{~V},+$ $0.875 \mathrm{~V})$; second scan for all samples.

Fig. 12. Cyclic voltammograms of aqueous solutions of (a) PMX2R $\left(4 \mathrm{~g} \mathrm{~L}^{-1}\right)$ and, (b) amaranth $\left(3 \mathrm{~g} \mathrm{~L}^{-1}\right)$ in $0.5 \mathrm{M} \mathrm{H}_{2} \mathrm{SO}_{4}$. Pt-Pani-Pt $\left(300 \mu \mathrm{g} \mathrm{cm}^{-2}\right)$ working electrode; scan rates $50,100,150,200,250,300,350,400,450$ and $500 \mathrm{mV} \mathrm{s}^{-1}$; range potential $(-0.2$ $\mathrm{V},+0.875) \mathrm{V}$; second scan for all samples.

Fig. 13. Adjust of $I_{p}$ vs. $v^{1 / 2}$ for the voltammograms obtained in Fig. 10. $I_{p}$ represents the value of the oxidation current of the dye in the corresponding cyclic voltammograms. Aqueous solutions of (a) PMX2R $\left(4 \mathrm{~g} \mathrm{~L}^{-1}\right)$ and, (b) amaranth $\left(3 \mathrm{~g} \mathrm{~L}^{-1}\right)$ in $0.5 \mathrm{M} \mathrm{H}_{2} \mathrm{SO}_{4}$. Pt-Pani-Pt $\left(300 \mu \mathrm{g} \mathrm{cm}^{-2}\right)$ working electrode; scan rates 50, 100, 150, 200, 250, 300, 350, 400, 450 and $500 \mathrm{mV} \mathrm{s}^{-1}$; range potential $(-0.2 \mathrm{~V},+0.875 \mathrm{~V})$; second scan for all samples.

\section{Table captions}

Table 1. XPS assignments of C1s, O1s, N1s and Pt4f core levels spectra for a Pt-Pani-Pt $\left(300 \mu \mathrm{g} \mathrm{cm}^{-2}\right)$ sample. 


\section{SUGGESTED REFEREES:}

1) Lin Niu. School of Chemistry and Chemical Engineering, Shandong University. e-mail: $\underline{\operatorname{lniu} @ \text { sdu.edu.cn }}$

Reason: He has worked with Pt nanoparticles and its dispersion on conducting polymers.

2) Carmen Gutiérrez-Bouzán. INTEXTER (Institut d'Investigació Tèxtil i Cooperació Industrial), Universitat Politècnica de Catalunya.

e-mail: gutierrez@intexter.upc.edu

Reason: She has worked extensively with dyes and its electrochemical treatment.

3) Assis Vicente Benedetti Ph. D.

UNESP - Univ Estadual Paulista, Institute of Chemistry.

e-mail: benedeti@iq.unesp.br

Reason: He has a large experience in Physical-Chemistry, particularly in electrochemistry of metals. 
a)

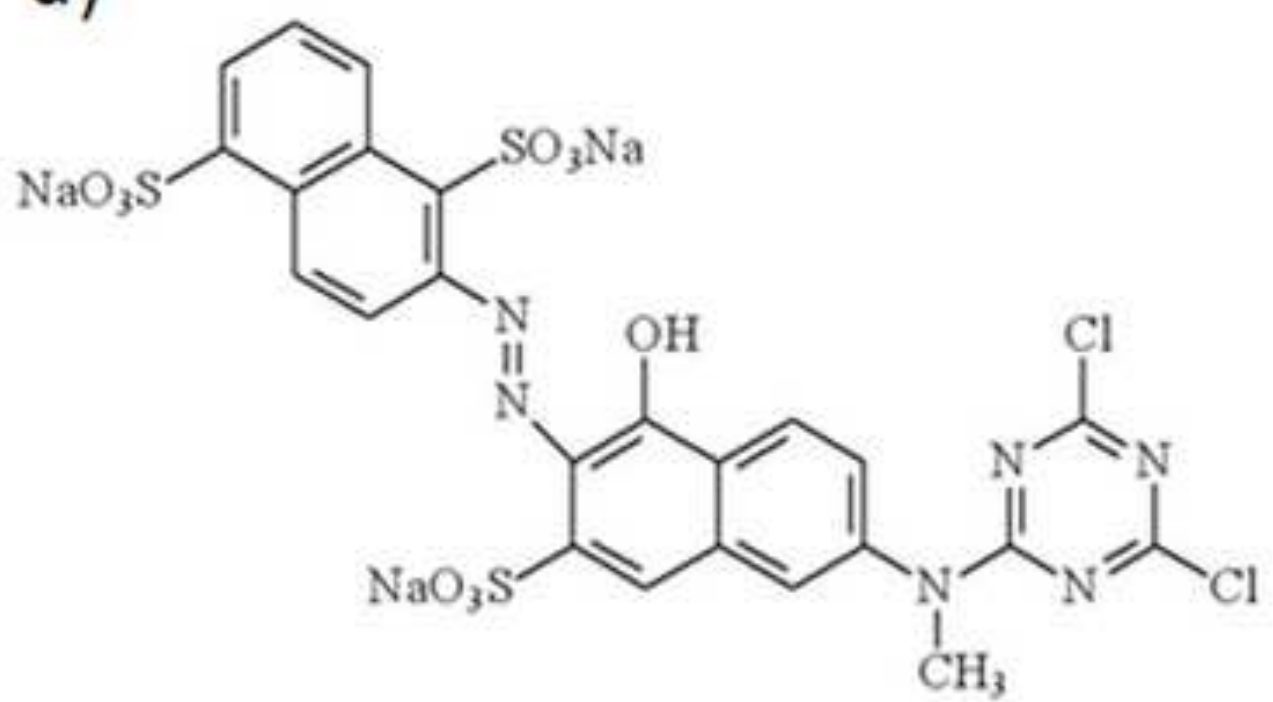

b)

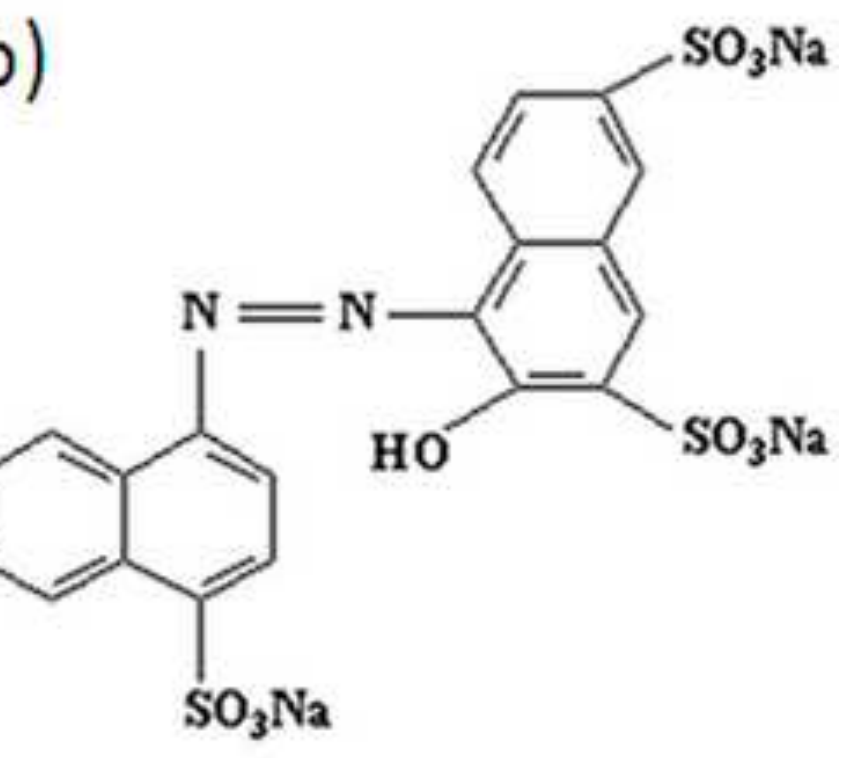



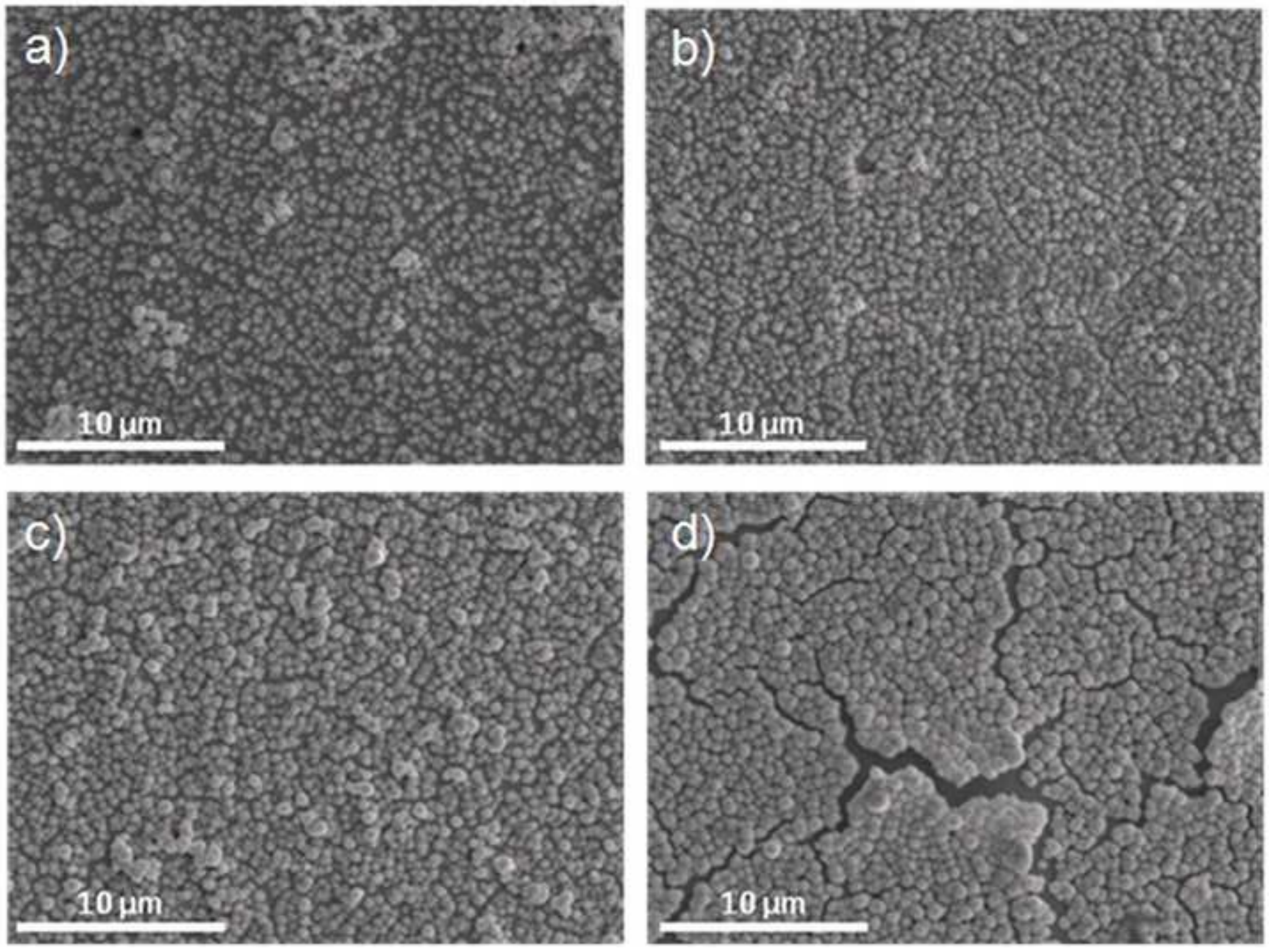
Figure(3)
Click here to download high resolution image
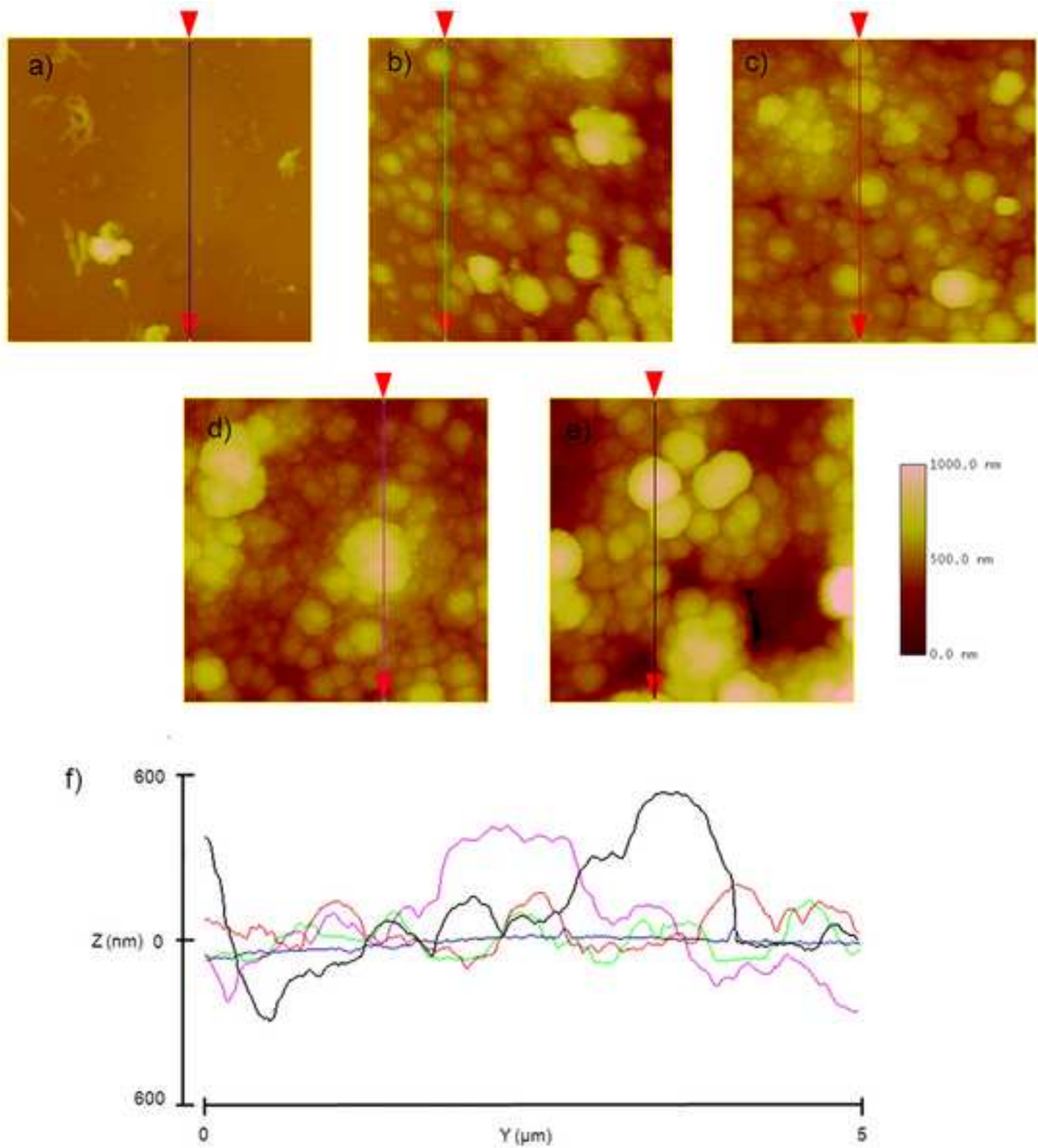

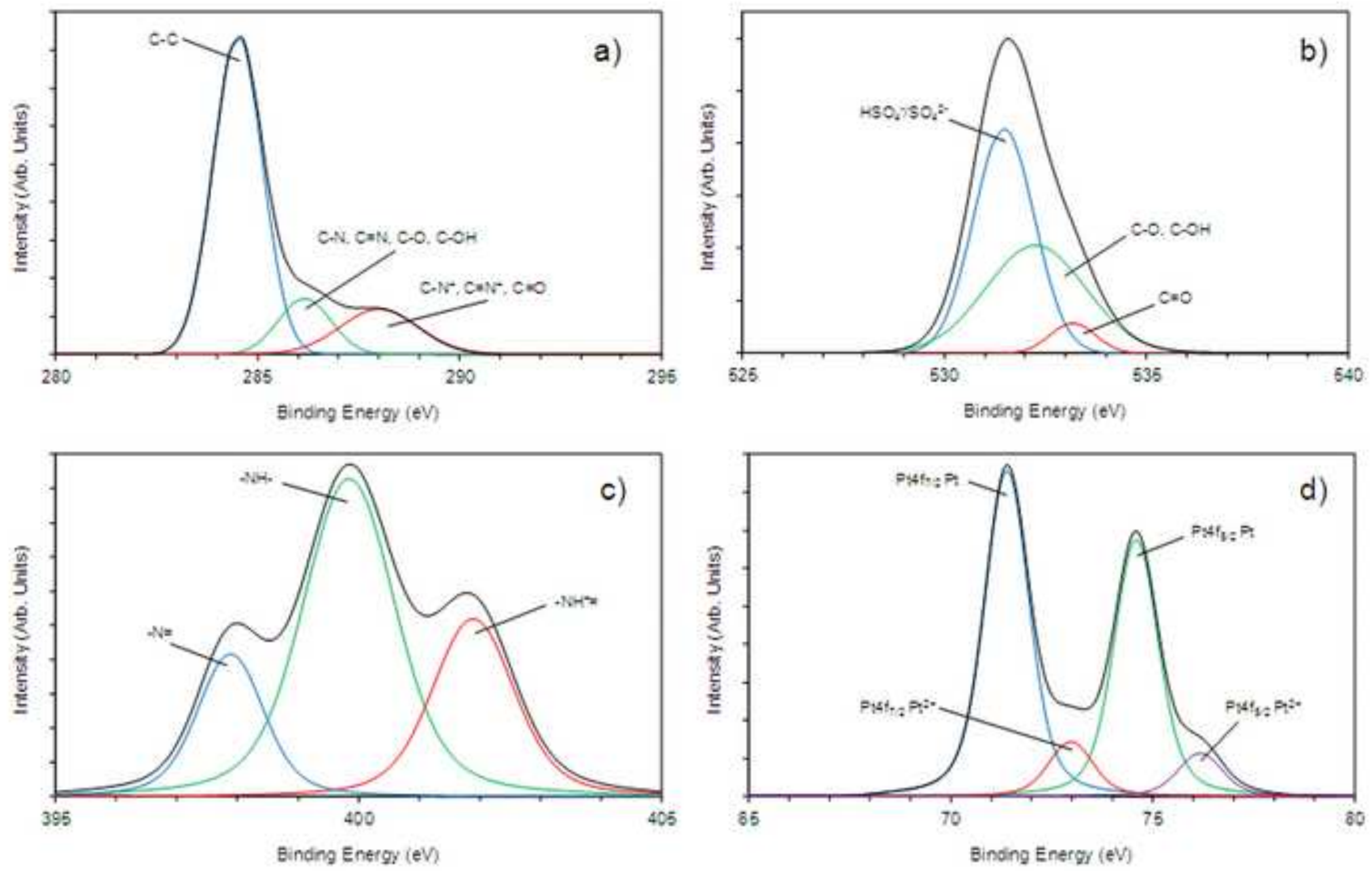


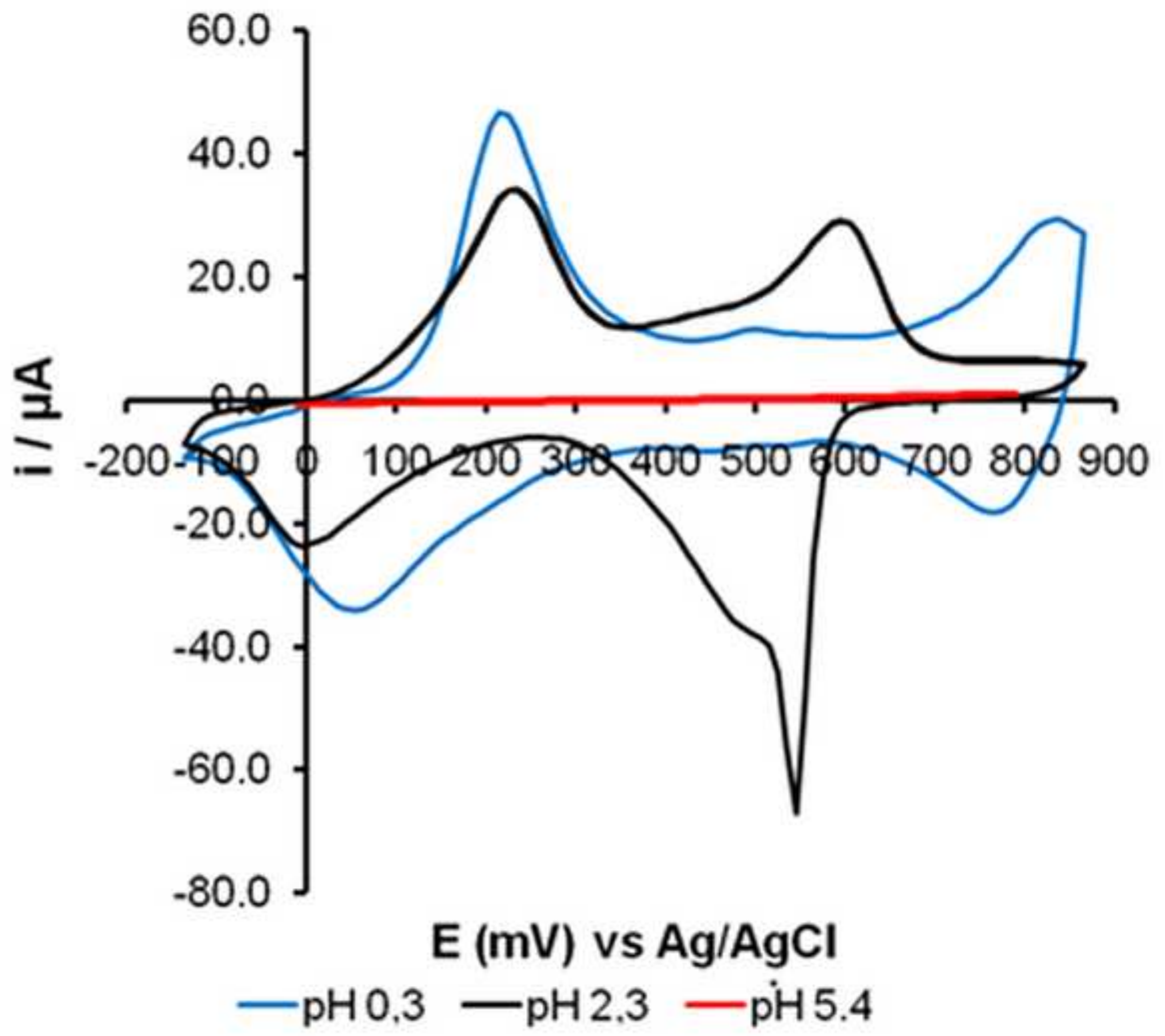


Click here to download high resolution image

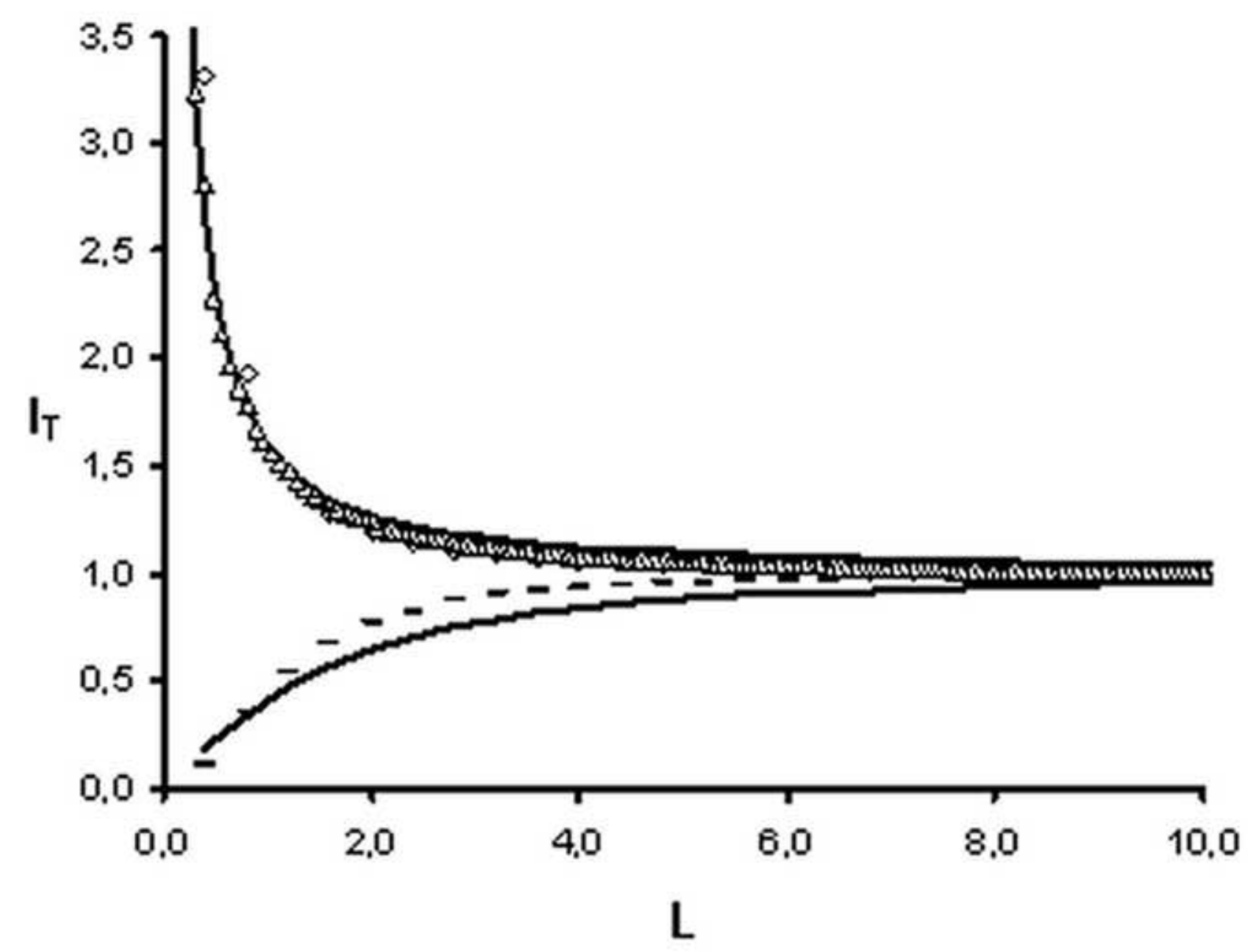


Click here to download high resolution image

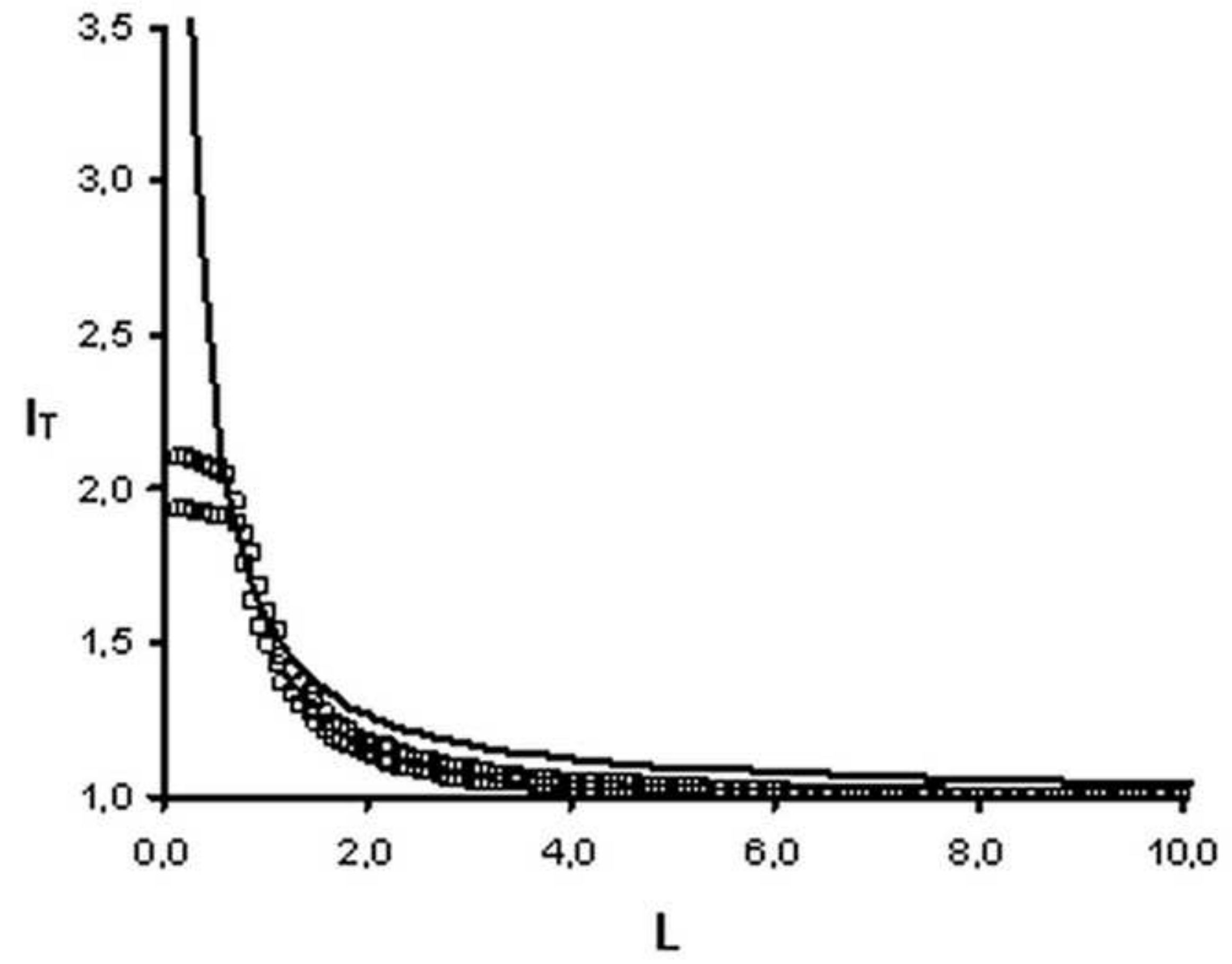



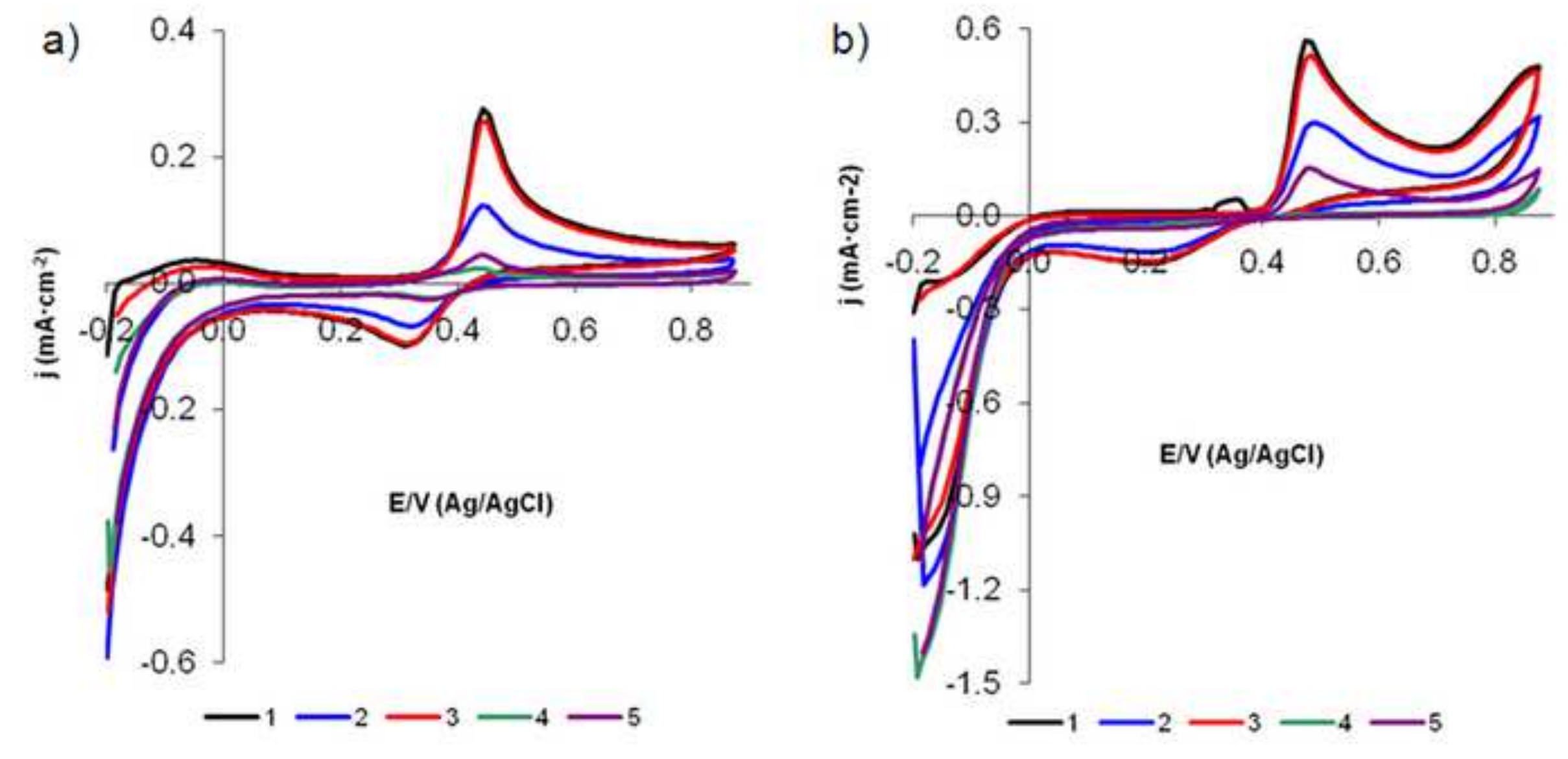

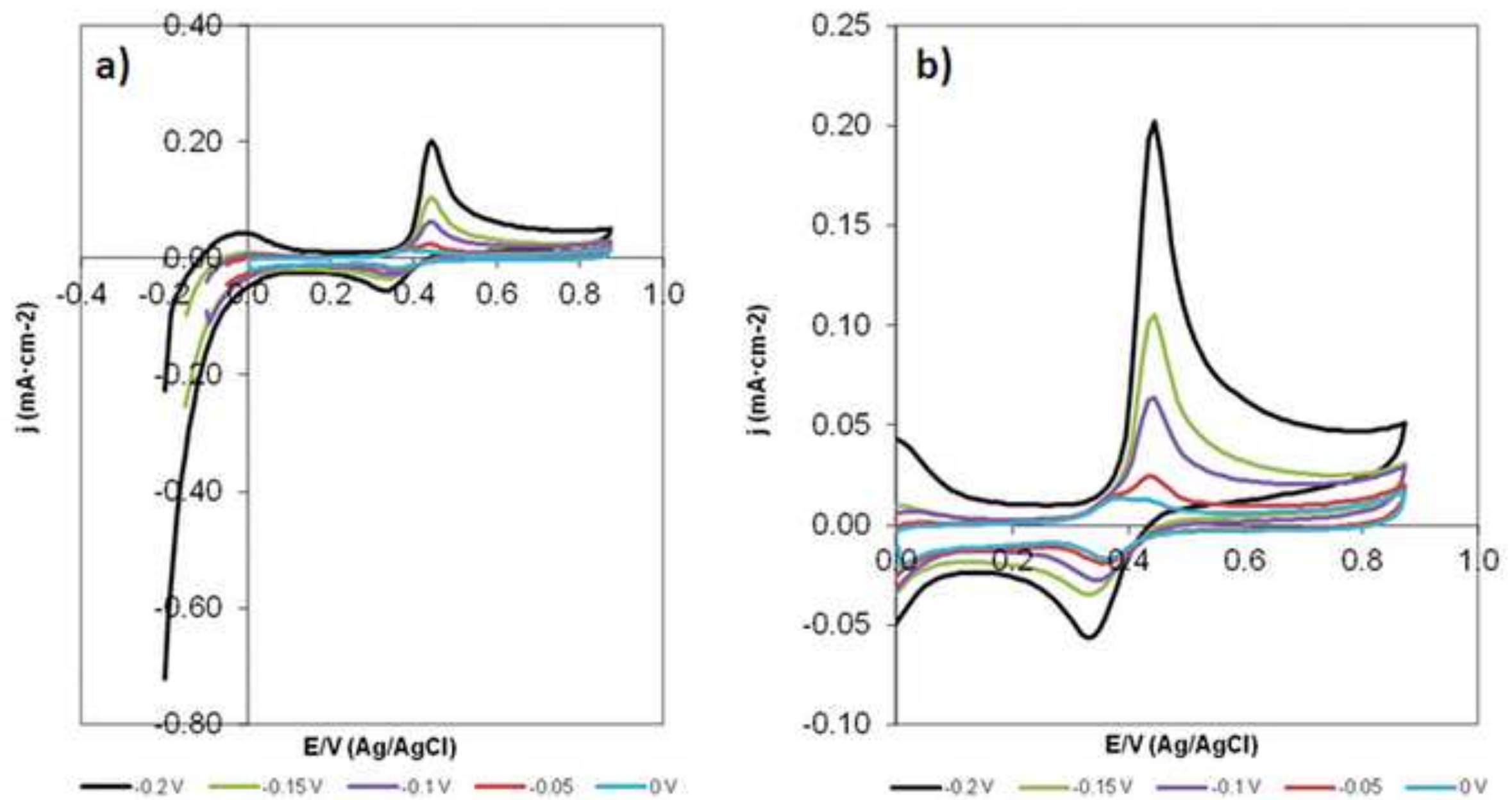

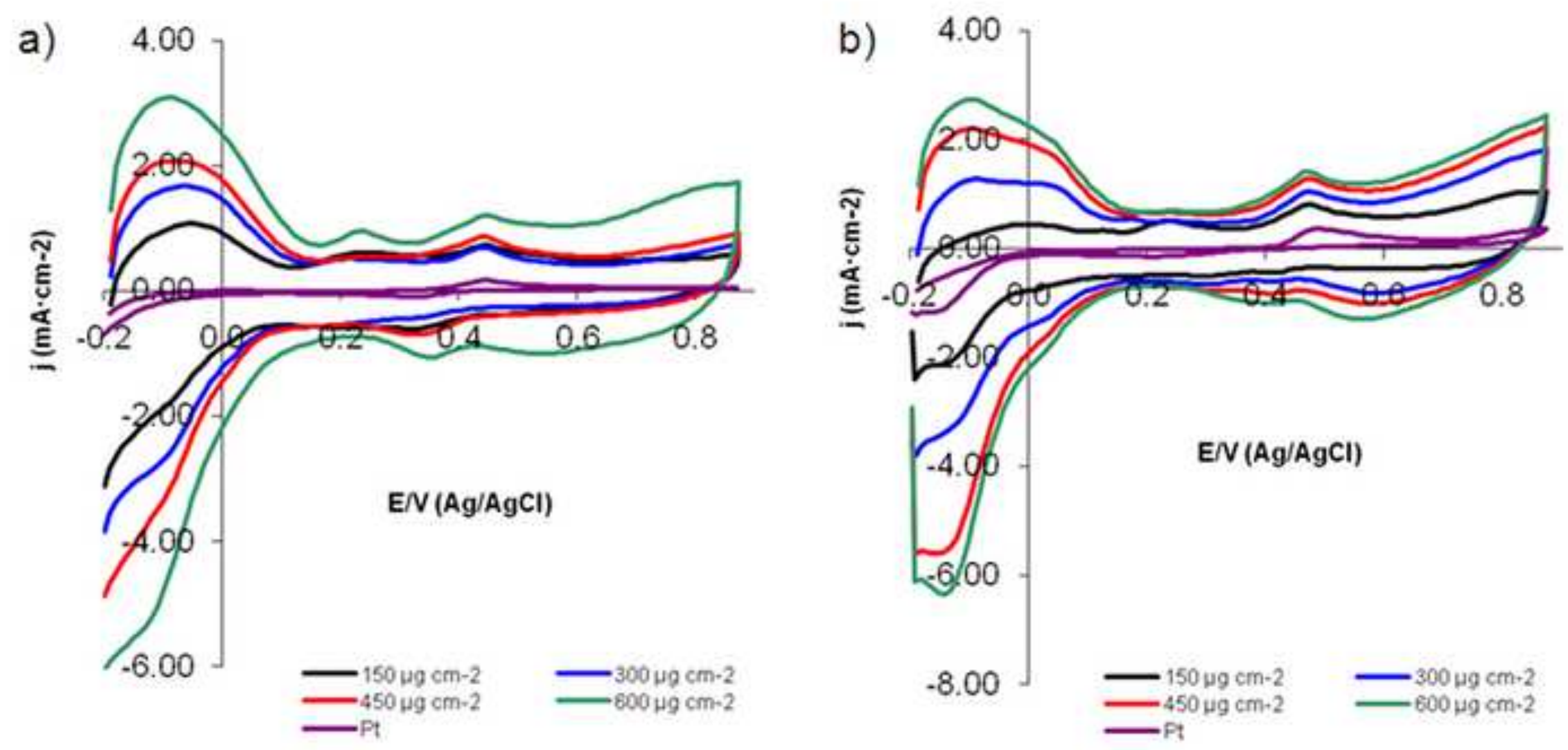

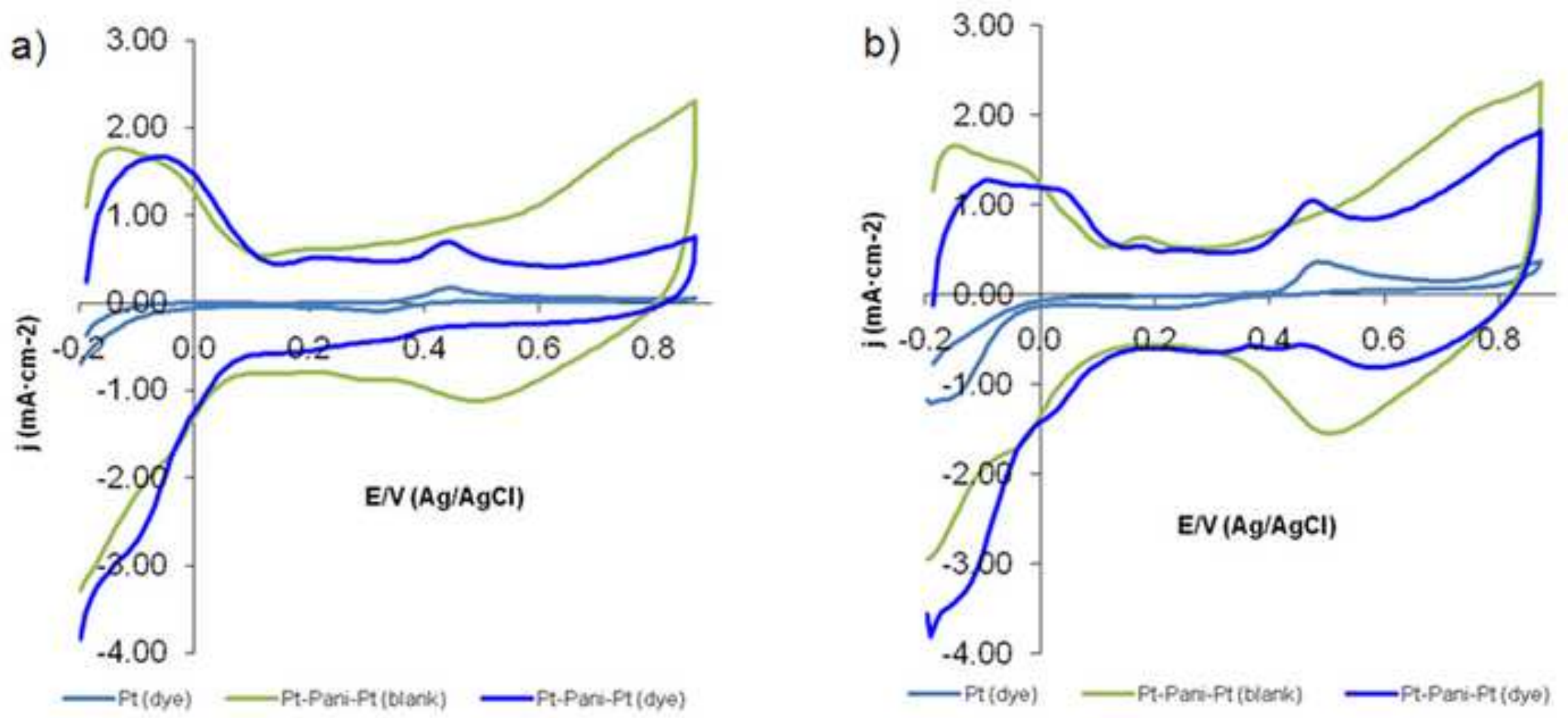
Click here to download high resolution image
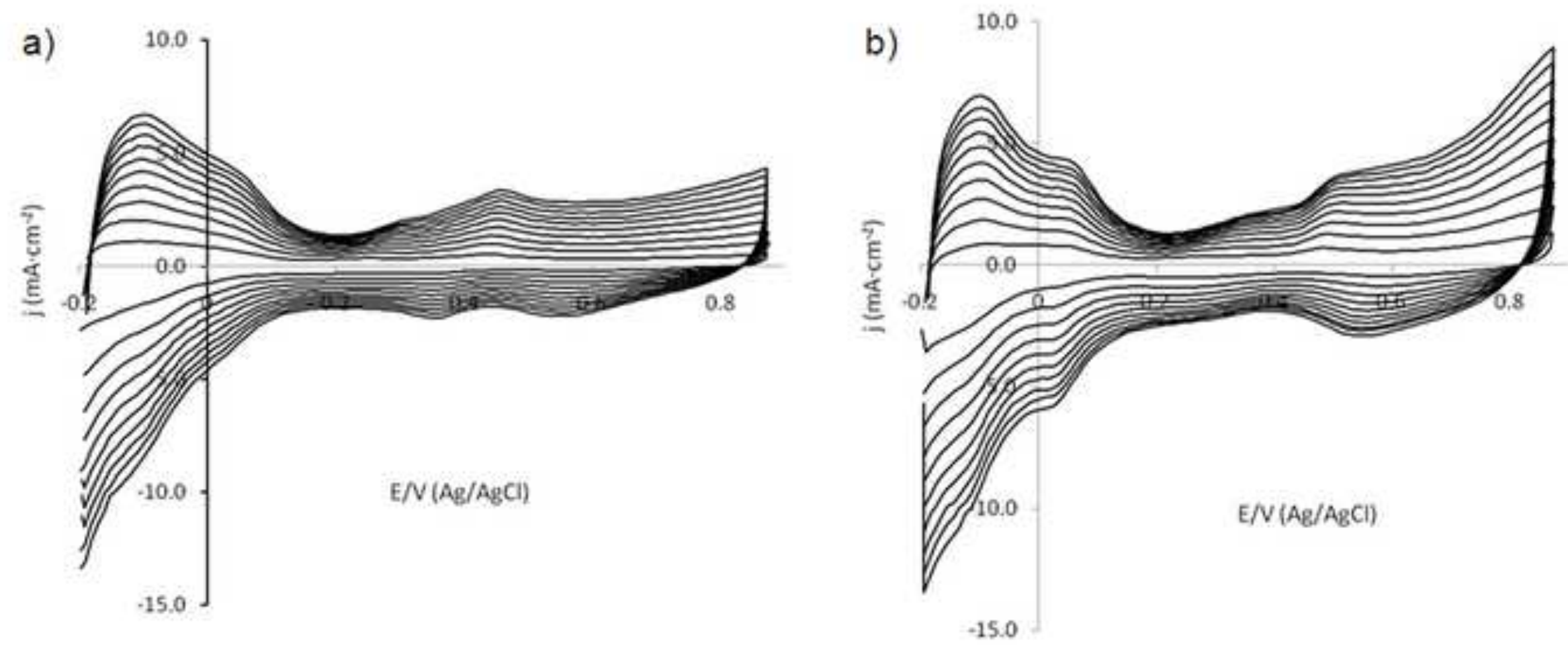
Click here to download high resolution image
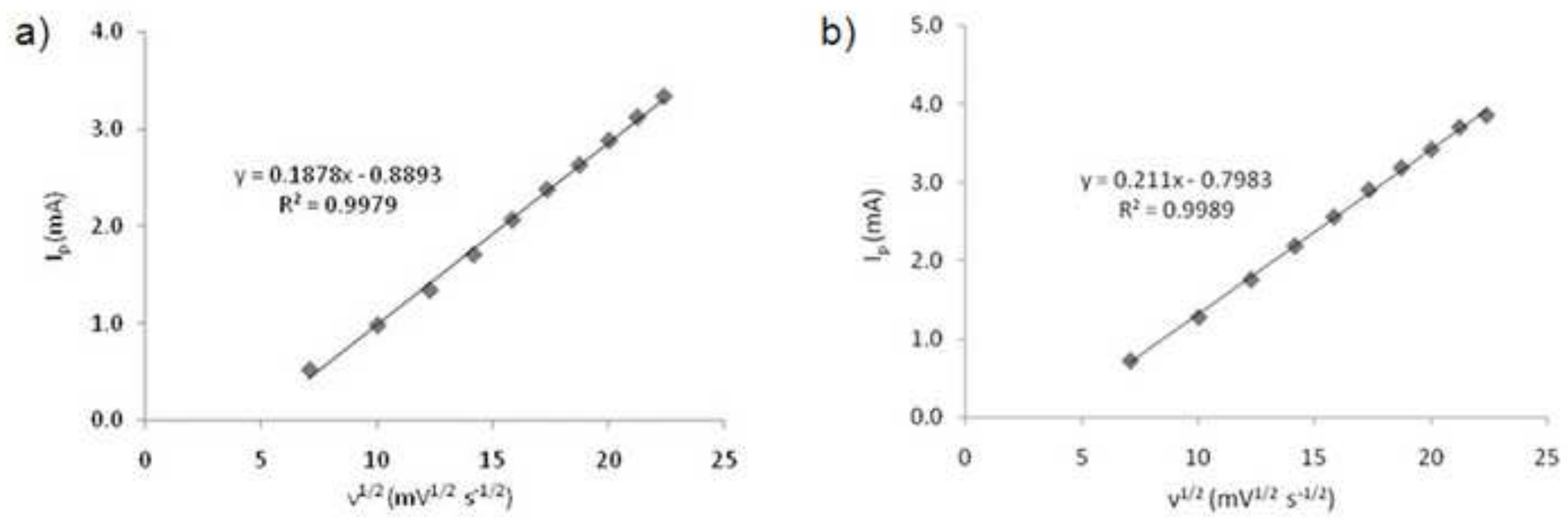


\begin{tabular}{|c|c|c|}
\hline & Pt-Pani-Pt & Assignments \\
\hline \multirow{3}{*}{$\mathrm{C} 1 \mathrm{~s}$} & 284.5 & $\mathrm{C}-\mathrm{C}$ \\
\hline & 286.2 & $\mathrm{C}-\mathrm{N}, \mathrm{C}=\mathrm{N}, \mathrm{C}-\mathrm{O}, \mathrm{C}-\mathrm{OH}$ \\
\hline & 288.0 & $\mathrm{C}-\mathrm{N}^{+}, \mathrm{C}=\mathrm{N}^{+}, \mathrm{C}=\mathrm{O}$ \\
\hline \multirow{3}{*}{ O1s } & 531.5 & $\mathrm{HSO}_{4} \cdot / \mathrm{SO}_{4}^{2-}$ \\
\hline & 532.3 & $\mathrm{C}-\mathrm{OH}, \mathrm{C}-\mathrm{O}$ \\
\hline & 533.2 & $\mathrm{C}=\mathrm{O}$ \\
\hline \multirow{3}{*}{ N1s } & 397.9 & $-\mathrm{N}=$ \\
\hline & 399.8 & $-\mathrm{NH}$ - \\
\hline & 401.9 & $-\mathrm{NH}^{+}=$ \\
\hline \multirow{4}{*}{ Pt $4 f$} & 71.4 & $\mathrm{Pt}^{\mathrm{O}}$ \\
\hline & 73.0 & $\mathrm{Pt}^{2+}$ \\
\hline & 74.6 & $\mathrm{Pt}^{0}$ \\
\hline & 76.2 & $\mathrm{Pt}^{2+}$ \\
\hline
\end{tabular}

